\title{
Copper and Zinc Homeostasis: Lessons from Drosophila melanogaster
}

\author{
Juan A. Navarro* and Stephan Schneuwly \\ Department of Developmental Biology, Institute of Zoology, University of Regensburg, Regensburg, Germany
}

Maintenance of metal homeostasis is crucial for many different enzymatic activities and in turn for cell function and survival. In addition, cells display detoxification and protective mechanisms against toxic accumulation of metals. Perturbation of any of these processes normally leads to cellular dysfunction and finally to cell death. In the last years, loss of metal regulation has been described as a common pathological feature in many human neurodegenerative diseases. However, in most cases, it is still a matter of debate whether such dyshomeostasis is a primary or a secondary downstream defect. In this review, we will summarize and critically evaluate the contribution of Drosophila to model human diseases that involve altered metabolism of metals or in which metal dyshomeostasis influence their pathobiology. As a prerequisite to use Drosophila as a model, we will recapitulate and describe the main features of core genes involved in copper and zinc metabolism that are conserved between mammals and flies. Drosophila presents some unique strengths to be at the forefront of neurobiological studies. The

Edited by:

David W. Killilea,

Children's Hospital Oakland Research Institute, United States

Reviewed by: Richard Burke,

Monash University, Australia Matthew D. Rand, University of Rochester, United States

${ }^{*}$ Correspondence:

Juan A. Navarro juan.navarro@ur.de

Specialty section: This article was submitted to Toxicogenomics, a section of the journal

Frontiers in Genetics

Received: 03 November 2017 Accepted: 11 December 2017 Published: 21 December 2017

Citation:

Navarro JA and Schneuwly S (2017) Copper and Zinc Homeostasis: Lessons from Drosophila melanogaster. Front. Genet. 8:223.

doi: 10.3389/fgene.2017.00223 number of genetic tools, the possibility to easily test genetic interactions in vivo and the feasibility to perform unbiased genetic and pharmacological screens are some of the most prominent advantages of the fruitfly. In this work, we will pay special attention to the most important results reported in fly models to unveil the role of copper and zinc in cellular degeneration and their influence in the development and progression of human neurodegenerative pathologies such as Parkinson's disease, Alzheimer's disease, Huntington's disease, Friedreich's Ataxia or Menkes, and Wilson's diseases. Finally, we show how these studies performed in the fly have allowed to give further insight into the influence of copper and zinc in the molecular and cellular causes and consequences underlying these diseases as well as the discovery of new therapeutic strategies, which had not yet been described in other model systems.

Keywords: Drosophila melanogaster, metal homeostasis, dMTF-1, methallothioneins, copper, zinc, in vivo modeling, human diseases

\section{INTRODUCTION}

\section{Drosophila melanogaster as a Model Organism}

The discovery of the first mutant allele of the gene white by TH Morgan (Morgan, 1910) meant the beginning of the Age of Drosophila as a pivotal model for the study of genetics, developmental biology and, more recently, of neurobiology and human diseases. Drosophila melanogaster is a small low-cost organism with a fast life cycle and a relatively short life span (Helfand and Rogina, 2003). Several ground breaking discoveries with strong impact on vertebrate neuroscience 
have endorsed Drosophila during the last century to become the model system of choice for many neuroscientists. Even before the genomic era, the fruit fly was pioneer in unveiling core elements of the nervous system development such as, among many others, Notch, Hedgehog, and Decapentaplegic (Jürgens et al., 1984; Wieschaus et al., 1984). The introduction of the P-elementmediated germline transformation (Rubin and Spradling, 1982) was another milestone in the history of Drosophila because it opened a new world of possibilities for genetic manipulations that culminated in 1991 and 1993 with the development of the flippase (FLP) and flippase recognition target (FRT) recombination (Golic, 1991) and the UAS/GAL4 (Brand and Perrimon, 1993) systems. Then, the publication of the first annotated version of Drosophila genomic sequence (Myers et al., 2000) confirmed that many human genes involved in all kinds of human diseases had an ortholog counterpart in the fly (Reiter et al., 2001). Moreover, genetic manipulation of those genes has successfully led to molecular, biochemical, tissue and behavioral defects that mirror the human conditions (Botella et al., 2009; Bouleau and Tricoire, 2015; Casci and Pandey, 2015; Xu et al., 2015). A remarkable example is the discovery of the molecular basis of behavior by characterization of genes controlling circadian rhythm and the biological clock (Konopka and Benzer, 1971). The impact of the characterization in the fly of the first clock gene, period (Bargiello and Young, 1984; Reddy et al., 1984) has been recently awarded with the Nobel Prize in Physiology or Medicine to Jeffrey C. Hall, Michael Rosbash and Michael W. Young. In addition, Drosophila has been instrumental in the characterization of the pathway controlling mitochondrial quality and integrity driven by the Parkinson's disease associated genes Pink and Parkin (Greene et al., 2003; Clark et al., 2006) or providing compelling information even if there was no identified paralogous gene as it is the case for $\alpha$-synuclein (Feany and Bender, 2000).

The last decades of fly research have boosted the generation of tools in the form of mutants, variants of the UAS-GAL4 system such as the GeneSwitch and the GAL80 inhibitor (Duffy, 2002), the generation of RNAi constructs to target genes in a tissue/cell-specific manner (Dietzl et al., 2007; Ni et al., 2009), the alternative Q system (Riabinina et al., 2015), and, of course, the possibility to create mutants at will by means of the clustered regularly interspaced short palindromic repeat/ endonuclease CRISPR-associated 9 (CRISPR/Cas9) system (Bassett and Liu, 2014). The implementation of these methodologies will allow the fly to continue being the leading model in the analysis of genes involved in human diseases.

\footnotetext{
Abbreviations: A $\beta$, A-beta; AD, Alzheimer's Disease; APP, amyloid precursor protein; BCS, bathocuproine disulfonate; BMP, Bone Morphogenetic Protein; $\mathrm{Cu}$, Copper; COX, Cytochrome c Oxidase; CRISPR/CAS9, clustered regularly interspaced short palindromic repeat/ endonuclease CRISPR-associated 9; ER, Endoplasmic Reticulum; FLP, Flippase; FRDA, Friedreich's Ataxia; FRT, Flippase Recognition Target; HD, Huntington's Disease; hh, Hedgehog; Htt, Huntingtin; KD, Knockdown; KSD, Kidney Stone Disease; LROs, Lysosomal Related Organelles; MRE, metal responsive element; Mtns, Methallothioneins; PD, Parkinson's Disease; Phm, peptidylglycine-hydroxylating monooxygenase;PrP, Prion Protein; qMtn, Quadruple mutant of MtnsA-D; ROS, Reactive Oxygen Species; SNPs, Single Nucleotide Polymorphisms; TGF $\beta$, Transforming
}

\section{Drosophila melanogaster as a Model to Study Metal Regulation and Homeostasis}

The number of manuscripts published using the fly to study the biology of metals is modest. However, the comprehensive work performed and being carried out in the labs of Walter Schaffner, Fanis Missirlis, James Camakaris, Bing Zhou, and Richard Burke has set up the foundations of the field, has provided invaluable translational evidences and has inspired many other fly researchers. Drosophila is extremely useful to analyze the regulation and toxicity of iron. Iron is essential to sustain life and it is the most important transition metal due to its cellular roles as electron donor in the oxidative phosphorylation and during photosynthesis. These roles have been detailed during the last decades as well as the impact of iron into several neurodegenerative diseases such as Friedreich's ataxia (FRDA), Parkinson's disease (PD) and neurodegeneration with brain iron accumulation disorders (Poujois et al., 2016). Importantly, the network of genes involved in iron biology and regulation is conserved between vertebrates and Drosophila with the exception of the Transferrin Receptor (reviewed in Mandilaras et al., 2013; Calap-Quintana et al., 2017). Fly studies have positively shown that targeting iron metabolism is sufficient to improve diseases conditions in models of FRDA (Navarro et al., 2015; Chen et al., 2016; Soriano et al., 2016), PD (Bonilla-Ramirez et al., 2011; Esposito et al., 2013; Zhu et al., 2016), or Alzheimer's disease (AD) (Rival et al., 2009; Liu et al., 2011; Ott et al., 2015). Besides iron, other functional studies have analyzed the regulation and homeostasis of other heavy metals (Maroni et al., 1986; AlMomani and Massadeh, 2005; He et al., 2009; Ortiz et al., 2009; Meyer et al., 2014; Rovenko et al., 2014; Ternes et al., 2014; Chandra et al., 2015; Guan et al., 2015; Niehoff et al., 2015). Of special interest is the recent work of Anholt's lab (Zhou et al., 2017) analyzing the genetic networks involved in the resistance to Cadmium and Lead toxicity. This work highlights that, metal homeostasis is much more complex than anticipated and that, $60 \%$ of the identified genes have human orthologs. In line with this complexity, fly models have proven that dysfunction of one single metal might be accompanied with dyshomeostasis of other ones. For example, increased aluminum in the fly food also alters iron toxicity (Wu et al., 2012).

In this review, we will focus on the biology of Zinc ( $\mathrm{Zn}$ ) and Copper $(\mathrm{Cu})$. We will summarize and discuss the main findings described in Drosophila regarding the cellular and organismal regulation of $\mathrm{Zn}$ and $\mathrm{Cu}$ with special insight into the nervous system, when possible. Moreover, we will also present a detailed review of the experiments performed with the fly to show the intimate relationship of both metals with human neurodegenerative diseases.

\section{GENERAL FACTS ABOUT Zn AND Cu}

Although the cellular roles of $\mathrm{Cu}$ and $\mathrm{Zn}$ are as important as those from iron, several aspects of their metabolism in the fruit fly are not as well characterized. $\mathrm{Cu}$ is an important

Growth factor beta; TGN, Trans-Golgi Network; TPEN, N,N,N'N'-tetrakis(2-pyridylmethyl)ethylenediamine; Tyr, Tyrosinase; Zn, Zinc. 
trace element necessary for living organisms because of its redox potential. Free $\mathrm{Cu}$ is able to inactivate cellular proteins by directly binding to cysteine residues (Letelier et al., 2009) and can promote oxidative stress and Reactive Oxygen Species (ROS), which will affect other cellular functions (Rotilio et al., 2000). Furthermore, $\mathrm{Cu}$ is an essential component of several enzymes (cuproenzymes) involved in diverse cellular processes. The existing literature has highlighted some of them: (i) Mitochondrial Cytochrome $\mathrm{C}$ oxidase (COX), a crucial gene for mitochondrial function; (ii) Peptidylglycine $\alpha$-amidating monooxygenase (PAM) and Dopamine beta $(\beta)$-hydroxylase $(\mathrm{DBH})$, involved in the biosynthesis of neurotransmitters; (iii) Lysyl oxidase (LOX), participating in the development of connectivity tissue; (iv) Tyrosinase (TYR), the rate-limiting enzyme in the biosynthesis of melanin, and (v) Superoxide Dismutase I (SOD1), one of the key cellular ROS scavengers (Zlatic et al., 2015; M Fetherolf et al., 2017). Altogether, $\mathrm{Cu}$ homeostasis is critical in skin pigmentation, integrity of blood vessels, myelination, maintenance of Purkinje cells, protection against oxidative stress and overall brain function via neurotransmitters (Harris, 2001; Opazo et al., 2014; Zlatic et al., 2015). Interestingly, $\mathrm{Cu}$ has also been described as a novel intracellular modulator of signal transduction pathways (Grubman and White, 2014). Accordingly, all this indicates the need of a strict regulation of $\mathrm{Cu}$ homeostasis.

$\mathrm{Zn}$ is also an essential trace metal with a huge panoply of biological roles and in turn with a strong impact on life. Opposite to $\mathrm{Cu}$ and iron, $\mathrm{Zn}$ is a redox-neutral element, which might exert antioxidant properties. It is a pivotal element for hundreds of enzymes in three different ways: as a key player of the catalysis (catalytic), as an enhancer of the reaction (coactivator) or by stabilizing the protein (structural) (Vallee and Falchuk, 1993). Zn plays key roles in metabolism of $\mathrm{CO}_{2}$ and alcohol, immunological capacity, endocrine response, development of organs and tissues, DNA and protein synthesis and cell division. Zn also participates in the autophagy process (Liuzzi et al., 2014) and therefore, in proteostasis, one of the most important hallmarks of aging. Moreover, $\mathrm{Zn}$ has been also described as a signaling molecule itself with important functions in the Bone Morphogenetic Protein (BMP) or the Transforming Growth factor beta (TGF- $\beta$ ) pathways (Osredkar, 2011; Choi and Bird, 2014). Finally, its role as a cofactor for hundreds of transcription factors that contain $\mathrm{Zn}$ finger domains is of paramount importance. Remarkably, both, its scarcity and accumulation, lead to cellular damage that might culminate in cell death. Therefore, $\mathrm{Zn}$ levels need to be tightly regulated to keep a precise balance and ensure bioavailability of $\mathrm{Zn}$ in each cell type.

\section{MTF-1 AND METALLOTHIONEINS: THE FIRST LINE OF DEFENSE}

$\mathrm{Cu}$ and $\mathrm{Zn}$ homeostasis relies on its correct acquisition, coordination between import and export, distribution and usage. Understanding the mechanisms underpinning metal sensing and regulation as well as deciphering the regulatory machinery is crucial to fully elucidate the biology of these metals. The transcription factor MTF-1 and the metal-binding proteins named Methallothioneins (Mtns) are common genes involved in the metabolism of $\mathrm{Cu}$ and $\mathrm{Zn}$ (Choi and Bird, 2014; Krezel and Maret, 2017).

\section{MTF-1}

In mammals, the metal-responsive transcription factor-1 (MTF-1) is the major mediator of protection against accumulation of $\mathrm{Zn}, \mathrm{Cu}$ and other heavy metals, by inducing the expression of genes that harbor several copies of the metal responsive element (MRE) in their promoters (Stuart et al., 1985). MTF-1 contains six zinc-finger domains and thus, requires $\mathrm{Zn}$ for its transcriptional activity. High $\mathrm{Zn}$ completely occupies all zinc fingers and then promotes the nuclear translocation of MTF-1. This property suggests, that MTF-1 might be working as a sensing molecule for Zn. Remarkably, MTF-1 also controls the response against oxidative stress, hypoxia, heat shock and even some nutritional alterations. Activation of MTF- 1 by these other stressors is not completely elucidated, but seems to be indirect either by a release of $\mathrm{Zn}$ from Mtns or by phosphorylation of certain residues (Günther et al., 2012a). Once MTF-1 is in the nucleus, it interacts with other cofactors or additional $\mathrm{Zn}$-dependent transcription factors to establish the specific expression profile according to the stressor (Krezel and Maret, 2017). In mammals, MTF-1 promotes the expression of several $\mathrm{Cu}$ and $\mathrm{Zn}$-related genes. Interestingly, it also increases the expression of proteins involved in iron metabolism (ferroportin and hepcidin) or in sensing the cellular redox status (glutamate cysteine-ligase, thioredoxin reductases, and selenoproteins) (Günther et al., 2012a). In mouse, MTF-1 has an essential function since constitutive MTF-1 knockout mice die at day 14 of gestation (Günes et al., 1998), whereas excision of MTF-1 after birth only increased mice susceptibility toward heavy metal stress (Wang et al., 2004). The knockout lethality has been related to a liver dysfunction due to abnormal hepatocyte differentiation rather than to metal toxicity, since knockout of Mtns yielded viable mice (Masters et al., 1994).

In Drosophila (Table 1; Figures 1, 2) such function falls on the shoulders of CG3743 (dMTF-1), that was first characterized by Walter Schaffner's lab (Zhang et al., 2001). Surprisingly, although MTF-1 is conserved throughout evolution, the degree of conservation between human and fly genes is only significant in the region containing the six zinc finger domains (81\%), whereas the rest of the proteins share only a small $23 \%$ of homology (Zhang et al., 2001). Despite these differences, fly dMTF-1 is able to replace the human counterpart in mammalian cell cultures and the human gene restores the tolerance to metals in $d M T F-1$ fly null mutants (Balamurugan et al., 2004). The seminal work from Walter Schaffner's group already showed in cell culture, that dMTF-1 was necessary and sufficient to activate the transcription of Mtns via MRE sequences (Zhang et al., 2001). Further works have shown that besides Mtns, iron (ferritin), Cu (DmATP7 and Ctr1B), and $\mathrm{Zn}(\mathrm{ZnT} 35 \mathrm{C})$ related genes are also transcriptionally activated by dMTF-1 (Southon et al., 2004; Selvaraj et al., 2005; Yepiskoposyan et al., 2006), suggesting that dMTF-1 participates in the acquisition and storage of metals. Similarly 
TABLE 1 | Drosophila proteins involved in Cu homeostasis (names according to Flybase, http://flybase.org).

\begin{tabular}{|c|c|c|c|}
\hline Fly gene & Cellular role & Human ortholog & $\begin{array}{l}\text { Related disease } \\
\text { fly model }\end{array}$ \\
\hline $\begin{array}{l}\text { Metal Transcription } \\
\text { factor- } 1^{*} \\
\text { dMTF-1 (CG3743) }\end{array}$ & $\begin{array}{l}\text { Control of } \\
\text { metal-dependent } \\
\text { transcription of } \\
\text { Mtns and some } \\
\text { Cu, Zn and iron } \\
\text { genes }\end{array}$ & $\begin{array}{l}\text { Metal Transcription } \\
\text { factor-1 (MTF-1) }\end{array}$ & $\begin{array}{l}\text { AD (Hua et al., } \\
2011 \text { b) } \\
\text { MD (Bahadorani } \\
\text { et al., 2010a) } \\
\text { FRDA (Soriano } \\
\text { et al., 2016) }\end{array}$ \\
\hline $\begin{array}{l}\text { Methallotioneins* } \\
\text { MtnA (CG9470) } \\
\text { MtnB (CG4312) } \\
\text { MtnC (CG5097) } \\
\text { MtnD (CG33192) } \\
\text { MtnE (CG42872) }\end{array}$ & $\begin{array}{l}\text { Cellular metal } \\
\text { (mainly } \mathrm{Cu} \text { ) } \\
\text { detoxification }\end{array}$ & $\begin{array}{l}M T-I \\
M T-I I \\
M T-I I I \\
M T-I V\end{array}$ & $\begin{array}{l}\text { FRDA (Soriano } \\
\text { et al., 2016) } \\
\text { AD (Hua et al., } \\
2011 b)\end{array}$ \\
\hline
\end{tabular}

\begin{tabular}{|c|c|c|c|}
\hline $\begin{array}{l}\text { Copper Transporter } \\
\text { Ctr1A (CG3977) } \\
\text { Ctr1B (CG7459) } \\
\text { Ctr1C (CG15551) }\end{array}$ & Cellular Cu uptake & $\begin{array}{l}\text { Solute carrier family } \\
\text { 31(SCL31A1) } \\
\text { hCTR1 }\end{array}$ & $\begin{array}{l}\text { AD (Lang et al., } \\
2013) \\
\text { HD (Xiao et al., } \\
\text { 2013) } \\
\text { MD (Bahadorani } \\
\text { et al., 2010a) } \\
\text { PD (Saini et al., } \\
\text { 2010) }\end{array}$ \\
\hline $\begin{array}{l}\text { ATPase } 7 \\
\text { DmATP7 (CG1886) }\end{array}$ & $\begin{array}{l}\text { Cellular Cu export } \\
\text { Cu delivery }\end{array}$ & $\begin{array}{l}\text { ATPase copper } \\
\text { transporting } \alpha \text { and } \beta \\
\text { (ATP7A and ATP7B) }\end{array}$ & $\begin{array}{l}\text { AD (Lang et al., } \\
\text { 2013) } \\
\text { HD (Xiao et al., } \\
\text { 2013) } \\
\text { MD (Bahadorani } \\
\text { et al., 2010a; } \\
\text { Southon et al., } \\
\text { 2010; Mercer } \\
\text { et al., 2017) } \\
\text { WD (Mercer et al., } \\
2017 \text { ) }\end{array}$ \\
\hline
\end{tabular}

\begin{tabular}{|c|c|c|c|}
\hline $\begin{array}{l}\text { Antioxidant } 1 \\
\text { copper chaperone } \\
\text { Atox1(CG32446) }\end{array}$ & $\begin{array}{l}\text { Chaperone. Cu } \\
\text { delivery to } \\
\text { DmATP7 }\end{array}$ & $\begin{array}{l}\text { Antioxidant } 1 \text { copper } \\
\text { chaperone (ATOX1) }\end{array}$ & $\begin{array}{l}\text { AD (Sanokawa- } \\
\text { Akakura et al., } \\
\text { 2010) } \\
\text { FRDA (Soriano } \\
\text { et al., 2016) }\end{array}$ \\
\hline $\begin{array}{l}\text { Copper Chaperone } \\
\text { for superoxide } \\
\text { dismutase } \\
\text { Ccs (CG17753) }\end{array}$ & $\begin{array}{l}\text { Chaperone. Cu } \\
\text { delivery to SOD1 }\end{array}$ & $\begin{array}{l}\text { Copper Chaperone } \\
\text { for superoxide } \\
\text { dismutase (CCS) }\end{array}$ & Not tested \\
\hline $\begin{array}{l}\text { Synthesis of } \\
\text { cytochrome c } \\
\text { oxidase } \\
\text { Scox (CG8885) }\end{array}$ & $\begin{array}{l}\text { Chaperone. Cu } \\
\text { delivery to } \\
\text { cytochrome c } \\
\text { oxidase }\end{array}$ & $\begin{array}{l}\text { Cytochrome c } \\
\text { oxidase copper } \\
\text { chaperone } \\
\text { (SCO1) }\end{array}$ & Not tested \\
\hline
\end{tabular}

Gene symbols for human genes follow the regulation of Human Genome Organization Gene Nomenclature Committee (http://www.genenames.org). *dMTF-1 and Mtns have been added in this table since their main role in Drosophila melanogaster is the detoxification of $\mathrm{Cu}$ accumulation. AD, Alzheimer's disease; FRDA, Friedreich's ataxia; $H D$, Huntington's disease; MD, Menkes disease; PD, Parkinson's disease; WD, Wilson's disease.

to the human protein, dMTF-1 has additional partners (Günther et al., 2012a) and phosphorylation sites (Gunther et al., 2012b) to allow the discrimination of target genes. Although MTF-1 and dMTF-1 cross-complement, some important differences have been observed. For example, dMTF-1 seems to be nuclear even under non-stress conditions (Gunther et al., 2012b) and it has a C-terminal domain that inhibits its hyperactivation (Gunther et al., 2012b). Moreover, dMTF-1 is essential to regulate $\mathrm{Cu}$ homeostasis via a cysteine cluster that works as a copper sensor (Chen et al., 2008).

Following the classical reverse genetic approach, mutant flies and flies overexpressing $d M T F-1$ have been generated to analyze its functions in Drosophila. Opposite to mouse, mutant $d M T F-1$ flies did not show any developmental defect, but presented a shorter longevity (Bahadorani et al., 2010b). Remarkably, they display an increased sensitivity toward accumulation of metals due to the lack of induction of the protective Mtns and the consequent accumulation of free metals in toxic concentrations (Egli et al., 2003, 2006b; Bahadorani et al., 2010b). In this line of events, $d M T F-1$ overexpression in central and peripheral nervous systems extended longevity under normal conditions, although no effect was observed upon expression in the gut (Bahadorani et al., 2010b). These results indicate that the control of metal homeostasis has a crucial tissue-specific component.

$\mathrm{Cu}$ and $\mathrm{Zn}$ show an unusual relationship with $d M T F-1$. On the one hand, $d M T F-1$ mutants are more sensitive to both $\mathrm{Cu}$ scarcity and supplementation, whereas overexpression increases resistance in both situations (Selvaraj et al., 2005; Bahadorani et al., 2010b). This dual role in detoxification and acquisition is likely related to the simultaneous control of the expression of the $\mathrm{Cu}$ importer $C \operatorname{tr} 1 B$ and the $\mathrm{Cu}$ exporter DmATP7 by dMTF-1 (Selvaraj et al., 2005; Yepiskoposyan et al., 2006; Burke et al., 2008; Bahadorani et al., 2010b). Activation of both might affect metal distribution and balance in a tissue-specific manner. On the other hand, dMTF-1 adult mutant flies are not sensitive to toxic concentrations of $\mathrm{Zn}$. However, overexpression of dMTF-1 ubiquitously, in the gut or in the neurons makes the flies hypersensitive to $\mathrm{Zn}$. Again, the explanation may rely in the induction of, at least, the zinc exporter ZnT35C by dMTF-1 (Yepiskoposyan et al., 2006). This induction will trigger aberrant ion distribution with depletion in some tissues and accumulation in others. In agreement, the overall amount of $\mathrm{Zn}$ was reduced in flies overexpressing dMTF-1 (Bahadorani et al., 2010b). These results suggested that nervous system and gut were particularly sensitive to perturbation of $\mathrm{Zn}$ homeostasis (Bahadorani et al., 2010b).

\section{Metallothioneins}

Mtns are ubiquitous, small cystein-rich proteins present from yeast to human with the ability to bind heavy metal ions and with thiol reactivity. Mtns are able to modulate their redox state in order to regulate metal bioavailability and buffer deleterious accumulation. Mammalian Mtns also respond to additional factors such as hormones, cytokines or oxidative stress. In humans up to 12 functional Mtns have been characterized, being MT-I to IV the most important family members (Palmiter, 1998; Krezel and Maret, 2017), whereas only five (A-E) have been found in the fruit fly (Egli et al., 2006a; Atanesyan et al., 2011). They carry out an essential metal detoxification because mutations and polymorphisms in Mtns are associated to human diseases ranging from diabetes, cancer, autoimmune diseases, 


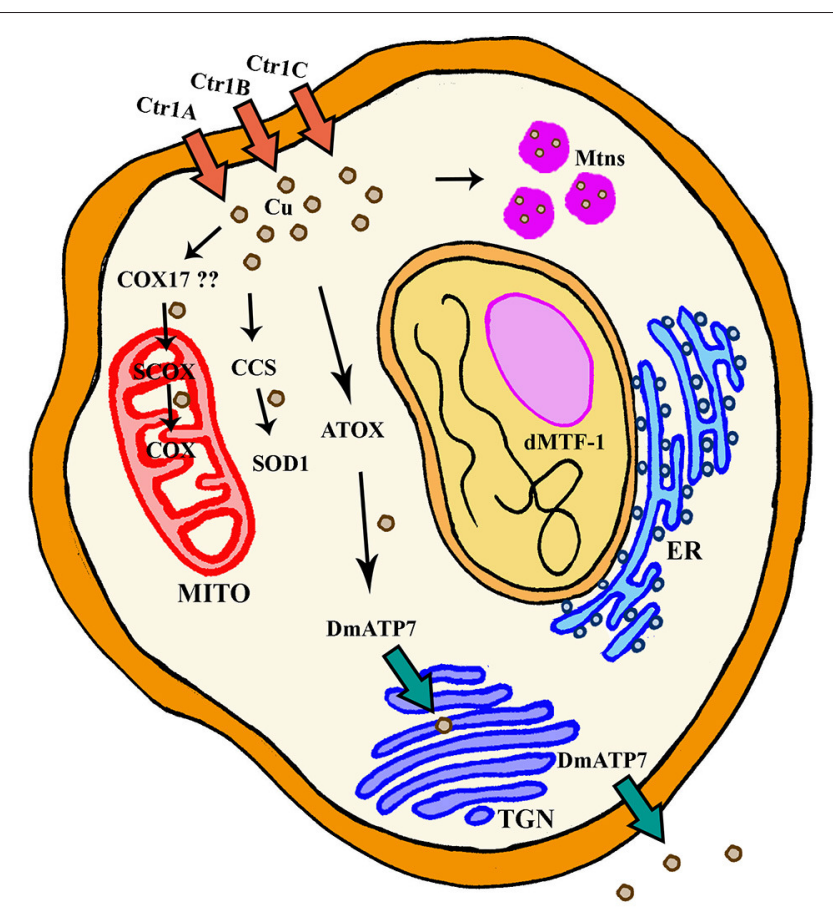

FIGURE 1 | General scheme of cellular Cu homeostasis in Drosophila melanogaster. ER, Endoplasmic Reticulum; Mito, Mitochondria; TGN, TransGolgi network.

neurodegenerative disorders and autism (Laukens et al., 2009; Raudenska et al., 2014). In mice, mutations in two Mtns do not induce lethality, but confer sensitivity toward Zn (Kelly et al., 1996).

Already in 1986, experiments in Drosophila larvae suggested the existence of genes with metal binding properties, whose expression was inducible by increasing concentration of metals (Maroni et al., 1986). Later on, the spectrum of stressors able to activate the expression of Mtns in flies was extended to thermal and oxidative stress (Bonneton et al., 1996). MtnA and B (firstly named as Mtn and Mto, respectively) were the first ones identified (Durliat et al., 1995) followed by MtnC and D (Egli et al., 2003) and more recently a fifth member (MtnE) was added (Atanesyan et al., 2011). In flies, all five Mtns (Table 1, Figures 1, 2) depend on dMTF-1 (Egli et al., 2003; Southon et al., 2004; Atanesyan et al., 2011) and are broadly conserved among the Sophophora and Drosophila subgenus (Guirola et al., 2011). MtnA shows the highest expression in all developmental stages (Atanesyan et al., 2011; Graveley et al., 2011). In larvae, all Mtns are expressed in larval gut, fat body, Malpighian tubules or salivary glands (Durliat et al., 1995; Egli et al., 2006b; Atanesyan et al., 2011). Increasing metal content in the fly food enhanced the levels of Mtn in those tissues and expanded the pattern to new regions. Expression in adult tissues is very poorly described with the exception of the work from Durliat and collaborators (Durliat et al., 1995). In this case, it was shown that MtnA and $\mathrm{B}$ were expressed in the adult cardia, gut or Malpighian and no expression was detected in other tissues. However, and in light of the increasing importance of metal detoxification in human diseases, a deeper analysis of Mtn expression in adults using new technical approaches and the fly tool box is of high interest. In this sense, we have detected robust expression of most of the Mtns in adult heads by Real Time-PCR (our unpublished observations).

Metal specificity is a critical issue regarding the biology of Mtns. Single, double, triple and quadruple mutants of MtnA-D (qMtn) have been generated to address this question (Egli et al., 2006a,b). Similarly to MTF-1, all Mtn mutants are viable and fertile. The analysis of developmental hypersensitivity to toxic metal concentrations in the different mutant combinations has provided valuable information. Those experiments revealed that MtnA and B are, respectively, essential to detoxify $\mathrm{Cu}$ and $\mathrm{Cd}$. $\mathrm{MtnC}$ and $\mathrm{D}$ did not seem to play a major role in protection (in agreement with their developmental expression) and $\mathrm{Zn}$ only had a minor impact even in the qMtn background. In contrast to $d M T F-1$ mutants, qMtn flies were not sensitive to $\mathrm{Cu}$ depletion, suggesting that Mtns are not essential for Cu import or to transfer $\mathrm{Cu}$. Regarding adults, qMtn flies show a strong hypersensitivity toward $\mathrm{Cu}$, but no information about other metals has been reported. MtnE responds to a broader range of metal including $\mathrm{Cu}, \mathrm{Zn}$, cadmium, silver and mercury (Pérez-Rafael et al., 2012). In accordance to this less specific induction, MtnE displays a broader expression pattern. This result might indicate that it could be important in a context, in which the other Mtns fail. This hypothesis is supported by the induction of MtnE expression in qMtn mutant (Atanesyan et al., 2011). Interestingly, a constant exposure to metals attenuates the initial boost of Mtn expression and this effect has not been detected in other dMTF-1 target genes (Egli et al., 2006b). The binding abilities of all five Mtns are different and nicely correlate with their responsiveness to toxic metal concentrations. All show low affinity to $\mathrm{Zn}$ and higher affinity to bind $\mathrm{Cu}$ and cadmium (Egli et al., 2006a; Pérez-Rafael et al., 2012). Anyways, quantification of expression levels of MtnB and $\mathrm{C}$ either by Real-Time PCR or by induction of a genetic reporter has been successfully used to monitor $\mathrm{Zn}$ levels in flies (Georgiev et al., 2010; Saini and Schaffner, 2010; Qin et al., 2013; Yin et al., 2017). We can conclude that fly Mtns act primarily as $\mathrm{Cu}$-thioneins in comparison to mammalian counterparts ( $\mathrm{Zn}$ thioneins) although several aspects of Mtn's cellular functions still need to be fully elucidated.

\section{REGULATION OF Cu METABOLISM}

Several proteins have already been described to participate in the $\mathrm{Cu}$ metabolism. In short, $\mathrm{Cu}$ is mainly imported via the copper transporter CTR1. $\mathrm{Cu}$ is then distributed by the copper chaperones, small proteins that deliver the metal to cuproenzymes such as SOD1 and cytochrome c oxidase, or to other members of the $\mathrm{Cu}$ regulatory network named ATP7A and ATP7B. These two P-type ATPases are also $\mathrm{Cu}$ donors to other $\mathrm{Cu}$-containing enzymes and participate in $\mathrm{Cu}$ extracellular delivery (Madsen and Gitlin, 2007). Drosophila has been used to study $\mathrm{Cu}$ biology since the early fifties (Poulson et al., 1952). Drosophila S2 cells express all classical genes involved in regulation (import, delivery and export) of $\mathrm{Cu}$ and their 


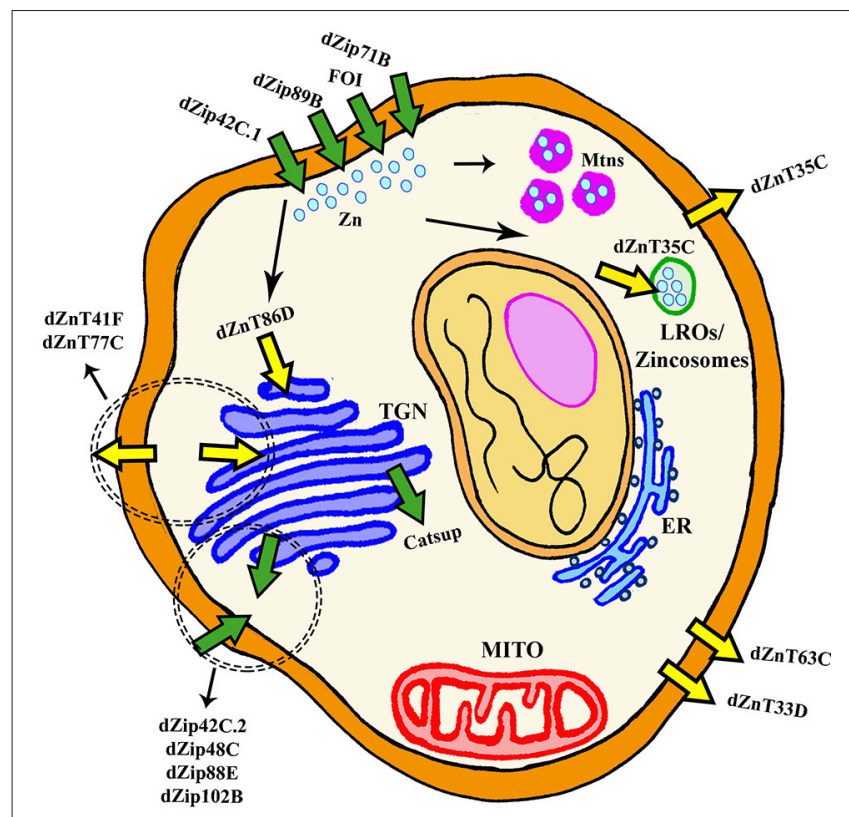

FIGURE 2 | General scheme of cellular Zn homeostasis in Drosophila melanogaster. ER, Endoplasmic Reticulum; Mito, Mitochondria; LROs, Lysosomal Related Organelles; TGN, TransGolgi network.

silencing altered $\mathrm{Cu}$ homeostasis as predicted, suggesting a conserved role. For example, knockdown (KD) of Ctr1B reduced $\mathrm{Cu}$ uptake and content, whereas downregulation of DmATP7 induced $\mathrm{Cu}$ accumulation due to a deficient efflux. As a result, the systemic $\mathrm{Cu}$ homeostasis is very similar between humans and Drosophila melanogaster (Southon et al., 2013a). Figure 1 and Table 1 summarize the key fly proteins involved in $\mathrm{Cu}$ metabolism. One of the main handicaps of the studies about $\mathrm{Cu}$ biology is the lack of proper and direct ways to measure $\mathrm{Cu}$ and to monitor differences either in the amount or in the distribution of the metal. Richard Burke's lab has very elegantly and nicely showed that synchrotron x-ray fluorescence microscopy is able to detect $\mathrm{Cu}$ alterations in a small organism such as Drosophila even in some tissues including the fly brain (Lye et al., 2011).

\section{Cu Uptake}

Copper transporter 1 (CTR1) is the main responsible of cellular import of Cu. CTR1 belongs to the SLC31 family of transporters and forms a trimeric channel to allow $\mathrm{Cu}$ uptake (Nevitt et al., 2012). The fly genome contains three different orthologs (Figure 1): Ctr1A, Ctr1B, Ctr1C (Zhou et al., 2003). Ctr1A is highly expressed throughout development, whereas $C \operatorname{tr} 1 B$ seems to be only relevant in late embryo and larvae with very strong expression in enterocytes (in order to uptake $\mathrm{Cu}$ from food). Ctr1C is very lowly expressed in all developmental stages and the expression seems to be mainly focused in male gonads (Zhou et al., 2003; Hua et al., 2010). All three proteins seem to be mainly localized in the plasma membrane (Selvaraj et al., 2005; Turski and Thiele, 2007; Binks et al., 2010; Steiger et al., 2010). In agreement, they are able to stimulate $\mathrm{Cu}$ import into Drosophila S2 cells (Zhou et al., 2003) and also in vivo (Balamurugan et al., 2007; Hua et al., 2010). Ubiquitous or panneuronal overexpression of any of the three genes is developmentally lethal, whereas eye-specific overexpression triggered a rough eye phenotype accompanied by neuronal degeneration (Balamurugan et al., 2007; Hua et al., 2010; Lang et al., 2013). This retinal degeneration is clearly related to $\mathrm{Cu}$ availability, since reducing $\mathrm{Cu}$ content in retinal neurons by increasing efflux (Balamurugan et al., 2007), enhancing $\mathrm{Cu}$ chelation by Mtns (Egli et al., 2006a), or with bathocuproine disulfonate (BCS) (Balamurugan et al., 2007; Hua et al., 2010) can rescue the phenotype.

Ctr1A seems to be the most important of all fly copper importers, since it displays the broadest expression pattern and its complete loss-of-function triggers developmental arrest (Turski and Thiele, 2007; Hua et al., 2010). In agreement with a reduced $\mathrm{Cu}$ import, $\mathrm{Ctr} 1 \mathrm{~A}$ deficient larvae and adults show lower activity of $\mathrm{Cu}$-requiring enzymes such as Cytochrome c Oxidases (Coxs), tyrosinase (Tyr) and peptidylglycinehydroxylating monooxygenase $(\mathrm{Phm})$. This resulted in lower pigmentation of mouth hooks and body, and reduced amidation of neurotransmitters (Turski and Thiele, 2007; Binks et al., 2010). Importantly, Cu-supplementation in the food (Turski and Thiele, 2007; Hua et al., 2010) or genetic manipulation of intracellular copper levels (Binks et al., 2010) improved some of the defects. Furthermore, the human counterpart hCtr1 also improved loss of $\operatorname{Ctr} 1 A$ conditions, suggesting a strong functional equivalence between both proteins (Hua et al., 2010). Due to the lethality associated to the complete depletion of $\operatorname{Ctr} 1 A$, tissue-specific experiments have also been performed. $\mathrm{KD}$ in the dorsal vessel generated a severe cardiomyopathy in the flies (Kim et al., 2010). This result demonstrates that cardiac defects present in several models of systemic $\mathrm{Cu}$ deficiency are a result of a tissuespecific effect. It is likely that, in a tissue highly dependent on mitochondria, strong reduction of Cox activity is underlying the cardiac defect. Ctr1A depletion in the nervous system showed that it is required for neuronal development (Binks et al., 2010). Interestingly, $\mathrm{KD}$ of $\operatorname{Ctr} 1 \mathrm{~A}$ in the protothoracic gland induced phenotypes reminiscent to a reduced Ras signaling. Accordingly, downregulation of $\operatorname{Ctr} 1 A$ was able to rescue the overactivation of Ras (Turski et al., 2012). Ctr1B is the only $\mathrm{Cu}$ importer identified as a direct target of dMTF-1 (Southon et al., 2004; Selvaraj et al., 2005). $C \operatorname{tr} 1 B$ is upregulated by $\mathrm{Cu}$ deprivation (Zhou et al., 2003) in order to maintain the correct systemic $\mathrm{Cu}$ amount and, unexpectedly, also by toxic accumulation of mercury and cadmium (Balamurugan et al., 2009). Mutants are viable but show hypopigmentation due to defects in the activity of the $\mathrm{Cu}$ containing enzyme Tyr. Since those mutants do not accumulate $\mathrm{Cu}$, they fail to induce the expression of Mtns (Zhou et al., 2003; Balamurugan et al., 2007). This defect is really $\mathrm{Cu}$ specific since mutants successfully promoted Mtns expression upon feeding with cadmium (Balamurugan et al., 2007). However, under conditions of $\mathrm{Cu}$ scarcity, mutants are unable to complete development (Zhou et al., 2003). In agreement with the specific expression pattern in the fly gut, a panneuronal $\mathrm{KD}$ of $\mathrm{Ctr} 1 B$ does not affect cellular integrity (Binks et al., 2010). Ctr1C is the least studied and its expression seems to be restricted to the 
maturing spermatocytes and the mature sperm. Ctr1C mutants are viable but their fertility is severely compromised in a $\mathrm{Cu}$ dependent manner (Steiger et al., 2010). Malvolio ( $M v l)$, the Drosophila homolog of Divalent metal transporter-1 (DMT1) is mostly involved in the transport of dietary iron in the gut (Folwell et al., 2006) but also seems to influence $\mathrm{Cu}$ content in Drosophila S2 cells (increased when overexpressed and reduced when depleted) and in the fly gut (Southon et al., 2008). Mutant individuals are viable but sensitive to increased levels of $\mathrm{Cu}$ in the food. Since its function might be redundant with members of the Ctr1 family, it is logical that the loss-of-function does not cause a systemic $\mathrm{Cu}$ deficiency.

\section{Cu Efflux}

In mammals, the responsibility to secrete $\mathrm{Cu}$ from cells relies on two P-Type ATPases, ATP7A, and ATP7B. They both belong to a group of genes that hydrolyze ATP to pump substrates across membranes (Zlatic et al., 2015). The fly genome only encodes one ortholog of mammalian ATP7A and B, DmATP7 (Figure 1) which displays a high homology (>45\%) to both ATPases (Southon et al., 2004). However, comparative genomic analysis of 12 Drosophila species shows that DmATP7 contains all the motifs existing in ATP7A required for localization and retention in the basolateral membrane, whereas ATP7B targeting motifs are not present (Southon et al., 2010). ATP7A has been described as a multitasking protein. It seems to be initially located in the transgolgi network (TGN), where it participates in the transfer of $\mathrm{Cu}$ into $\mathrm{Cu}$-containing proteins and it is relocated to the plasma membrane upon increasing concentrations of $\mathrm{Cu}$ (Kaler, 2011), where it is involved in cellular efflux of Cu. Several functional reporter constructs (DmATP7-lacZ, EYFP-DmATP7, UAS-DmATP7FLAG, gDmATP7:GFP) have been used to study the endogenous expression pattern of DmATP7. DmATP7 is highly expressed at the basolateral membrane of the $\mathrm{Cu}$ cells of the midgut and in the central, peripheral and enteric nervous system in all developmental stages. It is also expressed in the larval mouthparts, developing tracheae, the gut and in the malpighian tubules but not in the optic lobes, salivary glands and fat body. In the adult nervous system the expression in peptidergic neurons is of special importance due to the role of $\mathrm{Cu}$ in the biosynthesis of amidated neurotransmitters (Norgate et al., 2006; Burke et al., 2008; Sellami et al., 2012; Mercer et al., 2017). In all cases, fusion proteins show clear localization at the plasma membrane. Importantly, DmATP7 presents a $\mathrm{Cu}$ inducible and dMTF-1 dependent expression (Burke et al., 2008; Mercer et al., 2017). It is known that the $\mathrm{Cu}$-induced trafficking of mammalian ATP7A and ATP7B from the TGN toward the plasma membrane is critical for their role in $\mathrm{Cu}$ homeostasis (Kaler, 2011). Unexpectedly, this trafficking was not observed in cultured embryonic S2 cells, larval neuronal Bm3-c2 cells (Southon et al., 2010) or in vivo in larval midgut cells (Burke et al., 2008; Mercer et al., 2017) with any of the DmATP7 constructs. However, DmATP7 is able to translocate from the TGN to the plasma membrane when introduced in mammalian cells (Southon et al., 2010). Therefore, fly models still need to clarify whether such translocation is not required/necessary in flies or whether just current methodological limitations avoid its detection. In agreement with the expected role in $\mathrm{Cu}$ transport and export, coexpression of DmATP7 counteracted the phenotypes induced by the overexpression of the $\mathrm{Cu}$ importer $(C \operatorname{tr} 1 B)$ in the Drosophila retina (Balamurugan et al., 2007). Panneural overexpression of DmATP7 induced an altered morphology of neuromuscular junctions (Comstra et al., 2017) followed by a partial developmental lethality and a high percentage of unexpanded wings in the surviving adults due to a deficient activity of the corresponding neurotransmitters (Hwang et al., 2014). Similarly, ubiquitous overexpression induced body hypopigmentation due to the impairment of the $\mathrm{Cu}$-requiring enzyme Tyr (Norgate et al., 2006). Since all these effects are rescued by $\mathrm{Cu}$-supplemented food, we can conclude that overexpression also results in $\mathrm{Cu}$ deficiency due to increased efflux (Norgate et al., 2006; Hwang et al., 2014).

\section{Cu Chaperones}

In addition to transporters of $\mathrm{Cu}$ into and out of the cells, there is a third group of proteins with critical roles in $\mathrm{Cu}$ homeostasis. They are the so called " $\mathrm{Cu}$ chaperones" since their main role is to deliver $\mathrm{Cu}$ into aproproteins of cuproenzymes (Palumaa, 2013). Drosophila orthologs (Figure 1) of the mammalian $\mathrm{Cu}$ chaperones ATOX1, CCS, COX17 and SCO1, and SCO2 are found to be expressed in Drosophila S2 cells (Southon et al., 2004). Atox1 is the fly homolog of the mammalian ATOX1, which delivers $\mathrm{Cu}$ to ATP7A and ATP7B. In agreement, loss of Atox1 function in the flies phenocopies most of the defects of DmATP7 mutant flies (Hua et al., 2011a). CCS is the chaperone that delivers $\mathrm{Cu}$ to SOD1 ( $\mathrm{Cu} / \mathrm{Zn}$ superoxide dismutase). Ccs mutant flies display low levels of SOD1 activity, but also reduced levels of SOD1 protein. This important evidence suggests that Ccs plays a role in the stability of SOD1 (Kirby et al., 2008). SCO proteins are the $\mathrm{Cu}$ chaperones in charge of delivering $\mathrm{Cu}$ to the mitochondrial cytochrome c oxidase (COX). The Drosophila genome only encodes a single ortholog named Scox that is expressed during the whole development. Correspondingly, null mutants show a severely reduced COX activity that triggers developmental arrest at L2 stage. Hypomorphic alleles affect locomotion and female fertility, in agreement with its high expression in the egg chambers (Porcelli et al., 2010). It is likely that mitochondrial dysfunction is underpinning the loss-of-scox defects. However, additional studies will be needed to find out the complete mitochondrial mechanism. Unfortunately, although homologs of mammalian COX11 and COX17 have been found in silico, CG9065 and CG31648, and at least one of them is expressed in S2 cells (Southon et al., 2004), there is no report addressing their role in the $\mathrm{Cu}$ homeostasis or in the mitochondrial function.

\section{Cuproenzymes and Other Cu-Related Genes}

The classical enzymes described to require $\mathrm{Cu}$ in their activity, which have fly orthologs are: Lysyl oxidase, involved in connective tissue (Molnar et al., 2005); Peptidylglycine- $\alpha$-hydroxylating monooxygenase, involved in amidation of peptides (Hwang et al., 2014); Multi-copper oxidases MCO1 and MCO3, involved in iron homeostasis (Mandilaras et al., 2013); Tyramine $\beta$-Hydroxylase, involved in neurotransmitter synthesis (Monastirioti et al., 1996); 
tyrosine hydroxylase, involved in synthesis of melanine and dopamine (Wright, op. 1987) and $\mathrm{Zn} / \mathrm{Cu}$ superoxide dismutase (SOD1), involved in protection against oxidative stress (Phillips et al., 1989). SOD1 is by far the most studied in the fly, due to its strong relation with oxidative stress, aging and amyotrophic lateral sclerosis (ALS) (Renton et al., 2014; Casci and Pandey, 2015).

Moreover, in vivo screenings and microarray experiments have helped to identify new candidate genes involved in the regulation of $\mathrm{Cu}$. Syntaxin 5 was identified in a screening of genes that modulate mortality on excess $\mathrm{Cu}$ (Norgate et al., 2007). It is a soluble NSF attachment protein receptor (SNARE) gene involved in intracellular vesicle trafficking with high impact on $\mathrm{Cu}$ uptake (Norgate et al., 2010). Other similar examples are CG14036, CG11825, CG14545 (Norgate et al., 2007). VhaPPA1-2 and bib are a couple of genes that were first discovered as required for cuticle pigmentation and lately characterized as novel mediators of $\mathrm{Cu}$ biology that facilitate the membrane localization of $\mathrm{Cu}$ transporters (Mummery-Widmer et al., 2009; Wang et al., 2014). ADP-ribosylation factor 1, Adf1, contributes to maintain the golgi structure (Southon et al., 2011). Glutamatecysteine ligase catalytic subunit gene (Gclc) is the rate-limiting enzyme in glutathione (GSH) formation. GSH is a key cellular antioxidant molecule that also plays a role in $\mathrm{Cu}$ regulation (Mercer et al., 2016).

\section{REGULATION OF Zn METABOLISM IN DROSOPHILA}

Although $\mathrm{Zn}$ is an essential metal involved in a large panoply of key cellular processes, the in vivo physiological roles of $\mathrm{Zn}$ transporters are still not well characterized. In humans and in Drosophila, $\mathrm{Zn}$ homeostasis is mainly mediated by two large families of zinc transporters, the SLC39A or Zip (which import zinc into the cytoplasm) and the SLC30A or ZnT (which remove zinc from of the cytoplasm). Importantly, they are conserved throughout evolution from humans to flies (Lye et al., 2012). In silico and in vivo studies have identified up to 17 members of both families in the fly (Lye et al., 2013), whereas 24 proteins belong to those groups in mammals (Lichten and Cousins, 2009). In general, all $\mathrm{Zn}$ transporters in the fly are named by their cytological location (Yepiskoposyan et al., 2006) with the exception of catecholamines up (catsup) and fear of intimacy (foi) that retain their original names.

In the fly, most of the work to characterize the expression and function of dZip and $\mathrm{dZnT}$ genes has been performed in the Malpighian tubules and in the midgut because $\mathrm{Zn}$ mainly accumulates in the tubules and the gut is the primary site for the absorption of nutrients in Drosophila (Schofield et al., 1997). Therefore, global and systemic changes have been investigated in detail, but little is still known about local redistribution and availability of $\mathrm{Zn}$ within a given tissue or organ and even within the cell. Approaches based on genetic interactions have played an instrumental role in the identification of new genes involved in $\mathrm{Zn}$ homeostasis and in the analysis of the cellular and systemic roles of each transporter. Richard Burke's lab developed a brilliant strategy for this aim. They initially found that simultaneous overexpression of the main importer (dZip42C.1) and silencing of the main exporter ( $d Z n T 63 C)$ triggered $\mathrm{Zn}$ entrapment in the cytosol, that lead to a $\mathrm{Zn}$ toxic phenotype (named Ztox) characterized by either retinal degeneration and loss of eye pigmentation when carried out in the developing eye ( $g m r$-GAL4) or by scutellum loss, thorax cleft, hypopigmentation and bristles misaligned when performed in the developing thorax (pnr-GAL4) (Lye et al., 2012). Similarly, overexpression of $d Z n T 86 D$ or $d Z i p 71 B$ also induce changes in the eye morphology and pigmentation (Dechen et al., 2015). In parallel, Bing Zhou's lab conducted similar studies within the gut (Qin et al., 2013; Yin et al., 2017). Importantly, all these phenotypes were modulated (rescued or worsened) by chemical or genetic manipulation of Zn levels (Lye et al., 2012, 2013; Qin et al., 2013; Dechen et al., 2015; Yin et al., 2017). The genetic interactions showed which combinations of $\mathrm{Zn}$ transporters modified the eye morphology, the thorax pigmentation or the response toward $\mathrm{Zn}$ overload/depletion. All this information along with the subcellular localization described by reporter lines has allowed dividing the $\mathrm{Zn}$ transporters into four subgroups.

Table 2 and Figure 2 recapitulate all fly genes involved in $\mathrm{Zn}$ transport except dZnT49B. It shows sequence similarity to the hZIP9 gene but no other information about the gene is available and it cannot be properly classified. It is important to note, that the results from the interactions between the $\mathrm{Zn}$ toxic genotypes and the collection of RNAi constructs provides additional evidences about the expression pattern of the $\mathrm{Zn}$ transporters and complements the information available in the Flyatlas (flyatlas.org). In this sense, the results already reported (Lye et al., 2012, 2013; Dechen et al., 2015) suggest that almost all transporters are expressed in the developing eye, in the thorax or in the PNS.

\section{Importers of Extracellular Zn}

The proteins, which have been classified as pure $\mathrm{Zn}$ importers into the cytosol from the extracellular matrix are dZip42C.1 (dZip1), dZip89B, dZip71B and FOI (Figure 2). All genes of this category are localized in the plasma membrane (van Doren, 2003; Dechen et al., 2015). dZip42C.1 has been described as the main protein responsible for dietary $\mathrm{Zn}$ absorption in the midgut enterocytes (Lang et al., 2012; Qin et al., 2013). In parallel to this function, dZip42C.1 also participates in Zn import into the adult nervous system (Lang et al., 2012). Unexpectedly, reduction of $d Z i p 42 C .1$ in the gut did not trigger any deleterious effect, even under $\mathrm{Zn}$ depletion conditions. This strongly suggests the presence of other dZip proteins performing Zn uptake in the gut (Qin et al., 2013). Bioinformatic analysis showed that dZip89B and dZip42C.2 (that will be introduced in the next section) were the best candidates. In agreement, dZip89B increases cytosolic $\mathrm{Zn}$ levels when overexpressed (Lye et al., 2013; Dechen et al., 2015). Furthermore, flies lacking dZip89B are normal, although they show reduced $\mathrm{Zn}$ levels in the gut along with upregulation of dZip42C.1 and dZip42C.2. In addition, dZip89B has a broader expression pattern and works as a low-affinity $\mathrm{Zn}$ transporter (Richards et al., 2015). All this might explain the lack of sensitivity of dZip89B mutants to Zn deprivation. dZip71B performs the 
TABLE 2 | Drosophila proteins involved in Cu homeostasis (names according to Flybase, http://flybase.org).

\begin{tabular}{|c|c|c|c|}
\hline Fly gene & Cellular role & Human ortholog & $\begin{array}{l}\text { Related disease } \\
\text { fly model }\end{array}$ \\
\hline $\begin{array}{l}\text { dZip42C.1 (CG9428) } \\
\text { dZip89B (CG6898) } \\
\text { dZip71B (CG10006) } \\
\text { foi (CG6817) }\end{array}$ & $\begin{array}{l}\text { Cellular Zn } \\
\text { uptake }\end{array}$ & $\begin{array}{l}\text { hZIP1, hZIP2, hZIP3 } \\
\text { hZIP1, hZIP2, hZIP3 } \\
\text { hZIP5 } \\
\text { hZIP6, hZIP10 }\end{array}$ & $\begin{array}{l}\text { AD (Lang et al., } \\
\text { 2012; Huang } \\
\text { et al., 2014) } \\
\text { FRDA (Soriano } \\
\text { et al., 2016) } \\
\text { KSD (Chi et al., } \\
\text { 2015; Yin et al., } \\
\text { 2017) } \\
\text { PD (Saini and } \\
\text { Schaffner, 2010) }\end{array}$ \\
\hline $\begin{array}{l}\text { dZip42C.2 (CG9430) } \\
\text { dZip88E (CG4334) } \\
\text { Catsup (CG10449) } \\
\text { dZip48C (CG13189) } \\
\text { dZip102B (CG2177) }\end{array}$ & $\begin{array}{l}\text { Cytosolic Zn } \\
\text { uptake from } \\
\text { extracellular } \\
\text { matrix and } \\
\text { from } \\
\text { organelles }\end{array}$ & $\begin{array}{l}\text { hZIP1, hZIP2, hZIP3 } \\
\text { hZIP1, hZIP2, hZIP3 } \\
\text { hZIP7 } \\
\text { hZIP11 } \\
\text { hZIP9 }\end{array}$ & $\begin{array}{l}\text { FRDA (Soriano } \\
\text { et al., 2016) } \\
\text { PD (Chaudhuri } \\
\text { et al., 2007) }\end{array}$ \\
\hline $\begin{array}{l}d Z n T 63 C \text { (CG17723) } \\
d Z n T 33 D(C G 31860)\end{array}$ & $\begin{array}{l}\text { Cellular Zn } \\
\text { export }\end{array}$ & $\begin{array}{l}\text { hZnT1, hZnT10 } \\
\text { hZnT2, hZnT3, } \\
h Z n T 4, h Z n T 8\end{array}$ & $\begin{array}{l}\text { AD (Huang et al., } \\
\text { 2014) } \\
\text { FRDA (Soriano } \\
\text { et al., 2016) } \\
\text { KSD (Chi et al., } \\
\text { 2015; Yin et al., } \\
\text { 2017) } \\
\text { PD (Saini and } \\
\text { Schaffner, 2010) }\end{array}$ \\
\hline dZnT35C (CG3994) & $\begin{array}{l}\text { Cytosolic Zn } \\
\text { export outside }\end{array}$ & $\begin{array}{l}\text { hZnT2, hZnT3, } \\
\text { hZnT4, hZnT8 }\end{array}$ & $\begin{array}{l}\text { FRDA (Soriano } \\
\text { et al., 2016) }\end{array}$ \\
\hline $\begin{array}{l}d Z n T 41 F(C G 11163) \\
d Z n T 77 C \text { (CG5130) } \\
d Z n T 86 D(C G 6672)\end{array}$ & $\begin{array}{l}\text { of the cell or } \\
\text { into cellular } \\
\text { organelles }\end{array}$ & $\begin{array}{l}\text { hZnT2, hZnT3, } \\
\text { hZnT4, hZnT8 } \\
\text { hZnT1, hZnT10 } \\
\text { hZnT5, hZnT6, } \\
\text { hZnT7 }\end{array}$ & $\begin{array}{l}\text { KSD (Chi et al., } \\
\text { 2015; Yin et al., } \\
\text { 2017) } \\
\text { PD (Saini and } \\
\text { Schaffner, 2010) }\end{array}$ \\
\hline
\end{tabular}

Gene symbols for human genes follow the regulation of Human Genome Organization Gene Nomenclature Committee (http://www.genenames.org). AD, Alzheimer's disease; FRDA, Friedreich's ataxia; KSD, Kidney Stones disease; PD, Parkinson's disease.

opposite role to dZip42C.1 and its co-workers (dZip42C.2 and dZip89B). It is mainly expressed in the Malpighian tubules and imports $\mathrm{Zn}$ from the body for detoxification and disposal. Therefore, it is instrumental in the excretion of $\mathrm{Zn}$ from the organism and accordingly, silencing of $d Z i p 71 B$ triggers $\mathrm{Zn}$ accumulation in the body and these flies are more sensitive to $\mathrm{Zn}$ overload (Yin et al., 2017). When overexpressed, $d Z i p 71 B$ acts as a very efficient and potent $\mathrm{Zn}$ transporter able to create a toxic $\mathrm{Zn}$ accumulation on its own (Richards and Burke, 2015). Interestingly, both reports highlight cell-specific regulation of $\mathrm{Zn}$ metabolism.

FOI is not expressed in the gut, but is one of the cellular $\mathrm{Zn}$ importers in several other tissues (probably cooperating with dZip42C.1). The gene fear of intimacy (foi) showed up in genetic screens aiming to identify mutations affecting the development of fly gonads and trachea (van Doren, 2003; Mathews et al., 2005), embryonic nervous system (Pielage et al., 2004), and fly muscles (Carrasco-Rando et al., 2016). FOI is able to transport $\mathrm{Zn}$ in yeast and mammalian cells (Mathews et al., 2005). The Zn-related activity of foi is required for the stability of the cell-adhesion protein E-cadherin, that is essential for the proper formation of the gonads (Mathews et al., 2005, 2006). In the myoblast development, the expression of target genes of zinc-dependent transcription factors, such as Minc and Kruppel, was severely altered in foi mutants. In agreement, the phenotypes could be rescued by overexpression of other dZip genes with the same cellular localization such as $d Z i p 42 C .1$ and $d Z i p 71 B$ (CarrascoRando et al., 2016). All these results support the role of foi as a $\mathrm{Zn}$ transporter and the impact of its loss-of-function in the activity of zinc-finger transcription factors.

\section{Importers of Intracellular-Stored Zn}

This category includes proteins that, besides having some capacity to uptake $\mathrm{Zn}$ from the outside of the cell, they have been shown to remove $\mathrm{Zn}$ also from intracellular compartments. This group encompasses the following proteins dZip42C.2 (dZip2), dZip88E, CATSUP, dZip99C, dZip48C, and dZip102B (Figure 2). dZip42C.2 is another $\mathrm{Zn}$ importer from the lumen into the enterocytes (Qin et al., 2013). Flies with reduced dZip42C.2 levels were normal but they display severe phenotypes (more than those with reduced dZip42C.1) including developmental arrest under low zinc conditions. This suggests, that dZip42C.2 might play more crucial roles than its counterpart dZip42C.1. Interestingly, expression levels of both seem to be regulated by $\mathrm{Zn}$ levels in the enterocytes (Qin et al., 2013). dZip88E was initially thought to be the fourth member of this group formed by dZip42C.1, dZip42C.2, and dZip89B to absorb Zn from diet (Lye et al., 2012). However, its recent characterization (Richards et al., 2017) and the results from genetic interactions (Dechen et al., 2015), suggest a completely different role. It is expressed in a small subset of cells in the gut and larval CNS displaying both, plasma membrane and intracellular localization (Dechen et al., 2015; Richards et al., 2017). Interestingly, even with this restrictive expression, mutant flies are hypersensitive toward Zn. It seems that dZip88E expression in these cells acts as a surveillance system to detect $\mathrm{Zn}$ toxicity and elicit a systemic response to counteract it.

Catsup is another gene that was isolated long before it was described as a dZip gene (Stathakis et al., 1999). The name of the gene comes from the high levels of catecholamines of the mutant flies due to the hyperactivity of the tyrosine hydroxylase $(\mathrm{TH})$ enzyme. This result showed that Catsup is a negative regulator of dopamine synthesis. As a result, mutants display high synaptic activity and elevated mobility (Stathakis et al., 1999; Wang et al., 2011). Catsup has a very broad expression pattern (almost ubiquitous) and it is localized in the endoplasmic reticulum (ER) and Golgi apparatus (Groth et al., 2013). Accordingly, Catsup mutant flies accumulate misfolded proteins such as Notch and APPL in the Golgi apparatus and in the ER. Probably loss of catsup affects the normal processing and trafficking of proteins that, in turn, increases ER stress and caspase 3 activity (Groth et al., 2013). The genetic interactions suggest that Catsup participates in the transport of extracellular $\mathrm{Zn}$ and Zn efflux from Golgi apparatus (Dechen et al., 2015). $\mathrm{Up}$ to now, the relation of $\mathrm{Zn}$ with the synthesis of dopamine 
and the accumulation of misfolded protein in Catsup mutants has not yet been established. $d Z i p 99 C$ is a special case. It is classified in this group due to the results of genetic interactions (Dechen et al., 2015). However, recent research has found that it is an iron supplier and not a $\mathrm{Zn}$ transporter (Xiao et al., 2014). However, we cannot exclude that dZip99C is able to change $\mathrm{Zn}$ distribution indirectly. This would also explain the modification of $\mathrm{Zn}$ toxic phenotypes described in the literature (Lye et al., 2012, 2013; Dechen et al., 2015). Unfortunately, there is no functional data regarding dZip48C and dZip102B besides the information present in the FlyAtlas.

\section{Cellular Zinc Exporters}

The proteins that act as exporters of $\mathrm{Zn}$ outside of the cell are dZnT63C (dZnT1) and dZnT33D (Figure 2). dZnT63C was first discovered in the transcriptomic analysis of the fly response to metal toxicity (Yepiskoposyan et al., 2006). It shares homology with human ZnT1 (25.6\% identity and $43.1 \%$ similarity) and it is the major responsible protein for $\mathrm{Zn}$ import from the gut into the body (Wang et al., 2009) although it is also expressed in other tissues such as developing eye (Lye et al., 2012), testis or salivary glands (Wang et al., 2009). As expected from the proposed function, flies with reduced $d Z n T 63 C$ accumulated $\mathrm{Zn}$ in the gut and have a $\mathrm{Zn}$ deficiency in the rest of the fly. In agreement, these flies are also sensitive to $\mathrm{Zn}$ deprivation. The gut tries to compensate the loss of $d Z n T 63 C$ by downregulating $d Z i p 42 C .1$ and $d Z i p 42 C .2$ to reduce $Z n$ uptake. dZnT63C is also found in the Malpighian tubules where it acts in $\mathrm{Zn}$ reabsorption into the body (Wang et al., 2009; Yin et al., 2017). The genetic interactions performed in the eye and in the thorax of the fly to modify Zn dyshomeostasis phenotypes (Lye et al., 2013), have classified dZnT33D as another cellular Zn exporter, although some intracellular localization seems to be present as well. However, no additional information about its cellular roles is available.

\section{Zinc Exporters into Cellular Compartments}

This last group comprises ZnT transporters that mediate Zinc efflux from the cytoplasm into cellular compartments but that also might retain the ability of cellular export. The members of this group are dZnT35C, dZnT41F, dZnT77C, and dZnT86D (Figure 2). $d Z n T 35 C$ was first described as a gene upregulated by cadmium and $\mathrm{Zn}$ in flies (Yepiskoposyan et al., 2006). More importantly, it was also identified in the transcriptomic profile of dMTF-1 mutants (Yepiskoposyan et al., 2006) as one of the targets of this transcription factor. Moreover, dZnT35C is sufficient to modulate total $\mathrm{Zn}$ content in the fly body. Null mutations and ubiquitous downregulation of $d Z n T 35 C$ leads to viable individuals that are more sensitive to $\mathrm{Zn}$ overload (Yepiskoposyan et al., 2006; Yin et al., 2017). This phenotype is in agreement with the suggested exclusive expression of $d Z n T 35 C$ in the Malpighian tubules and its role in $\mathrm{Zn}$ detoxification and secretion from the body (Yepiskoposyan et al., 2006; Chi et al., 2015; Yin et al., 2017). Loss of $d Z n T 35 C$ impairs $Z n$ detoxification and reduces, in turn, $\mathrm{Zn}$ tolerance. The ability of $\mathrm{KD}$ of $d Z n T 35 C$ to improve the eye degeneration induced by $d Z i p 71 B$ (Dechen et al., 2015) also suggests neuronal expression in photoreceptor cells. Although dZnT35C has been localized in the plasma membrane, a recent and very interesting result confers $d Z n T 35 C$ a new location and a new role. $d Z n T 35 C$ is pivotal for the formation of a specialized type of lyososomal related organelles (LROs) in the Malpighian tubules that store Zn (Tejeda-Guzmán et al., 2017). These LROs might be the fly equivalent of mammalian zincosomes (Zalewski et al., 1993). The possibility to transport metals via vesicle-like structures has already been reported for mammalian ATP7A (Lutsenko et al., 2007).

$d Z n T 86 D$ is a $\mathrm{Zn}$ transporter located in the Golgi apparatus. Its overexpression is able to produce $\mathrm{Zn}$ toxic phenotypes in the eye without any further genetic modification (Dechen et al., 2015). Therefore, is a very interesting tool to analyse the effects provoked by $\mathrm{Zn}$ accumulation in the Golgi as well as changes in the intracellular $\mathrm{Zn}$ distribution. The ubiquitous downregulation is lethal and also produces thorax and rough eye phenotypes when performed in a tissue-specific manner (Lye et al., 2012, 2013). All this suggests that $\mathrm{Zn}$ plays fundamental roles in the Golgi. The last two dZnT genes, $d Z n T 77 C$ and $d Z n T 41 F$, were classified in this category according to the results of the genetic interactions (Lye et al., 2012, 2013; Dechen et al., 2015). However, very little is known regarding their roles in the organismal and cellular $\mathrm{Zn}$ metabolism. On the one hand, dZnT77C is also localized in the plasma membrane of midgut cells and collaborates with dZnT63C in supplying Zn to the body from the fly intestine (Qin et al., 2013). As expected, ubiquitous silencing also enhances $\mathrm{Zn}$ toxicity and worsens phenotypes derived from $d Z n T 63 C \mathrm{KD}$. On the other hand, $d Z n T 41 F$ is also expressed in the Malpighian tubules (Chi et al., 2015; Yin et al., 2017). The similarities between silencing of $d Z n T 41 F$ and $d Z n T 63 C$ in the Malpighian tubules suggested that $d Z n T 41 F$ also contributes to body $\mathrm{Zn}$ reabsorption (Yin et al., 2017).

\section{Other Genes}

Additional genes that do not belong to the ZnT/Zip families have also been identified. The single Drosophila TRPM gene $(d T R P M)$ is a curious example. Georgiev and collaborators found that $d T R P M$ is permeable to $\mathrm{Zn}$. $d T R P M$ deficiency triggered a strong decrease in cell size that clearly resembles the effects of cellular $\mathrm{Zn}$ deficiency in control flies. Further experiments suggested that $A T R P M$ regulates $\mathrm{Zn}$ homeostasis in a specific cellular compartment that is pivotal to growth control (Georgiev et al., 2010). Other very interesting cases are the Drosophila aquaporin homolog big brain (bib) and vhaPPA1-2, a subunit of the vacuolar-type ATPase. KD of vhaPPA1-2 or bib reduced sensitivity to high dietary zinc levels. Their study showed loss of these two genes altered the correct subcellular localization of zinc transporters. The defect in this new level of control of $\mathrm{Zn}$ homeostasis was probably due to a failure in the endosomal recycling of proteins back to the membrane that hence reduced the uptake of $\mathrm{Zn}$ (Wang et al., 2014). Very recently, kuzbanian $(k u z)$ a gene that was already described as a target of $d M T F-1$ (Yepiskoposyan et al., 2006) has been found to confer tolerance to $\mathrm{Zn}$ when overexpressed (Le Manh et al., 2017).

The unexpected finding of abnormal $\mathrm{Zn}$ levels in a heterozygous fumble mutant (Gutiérrez et al., 2010) lead to 
the identification of an unknown recessive factor on the $\mathrm{X}$ chromosome displaying a strong influence on the organismal $\mathrm{Zn}$ content (Afshar et al., 2013). This mutation has been named pocozinc in the unpublished observations of Fanis Missirlis'group (Tejeda-Guzmán et al., 2017). Although no definitive evidence was presented, all results point toward the white gene as the responsible for the poco-zinc phenotype. Following this initial discovery, authors realized that other mutants of genes involved in the transport of eye pigments, such as scarlet (st) or carmine $(\mathrm{cm})$, also display reduced $\mathrm{Zn}$ levels. It seems that the collective action of most of these proteins is required for the biosynthesis of $\mathrm{Zn}$ storage granules in the Malpighian tubules of Drosophila (Tejeda-Guzmán et al., 2017) and thus to maintain systemic Zn homeostasis. Remarkably, the process of characterization of the poco-zinc locus has also highlighted the crucial importance of controlling the genetic background of flies in order to avoid misinterpretation of results when analyzing $\mathrm{Zn}$ metabolism and comparing different genotypes. Finally, in a recent publication from Norbert Perrimon's lab, a Drosophila cell-based RNAiscreen has allowed the identification of novel genes conferring sensitivity or protection toward Zn such as CG11897 (red dog mine, $r d o g$ ) and some disease-related genes such as IA-2 protein tyrosine phosphatase, an ortholog of human PTPRN or CG32000, a putative ortholog of human ATP13A2 (Mohr et al., 2017).

\section{THE ROLE OF Cu AND Zn IN DROSOPHILA MODELS OF HUMAN NEURODEGENERATIVE DISEASES}

$\mathrm{Cu}$ also exerts some specific roles in the nervous system. $\mathrm{Cu}$ is necessary in flies and mammals for the biosynthesis of neurotransmitters (Sellami et al., 2012; Opazo et al., 2014) and thus, for brain activity. In addition, $\mathrm{Cu}$ modulates and even blocks the activity of receptors involved in neurotransmission such as NMDA, AMPA or GABA. It has been suggested that these synaptic roles are mediated by interplays between $\mathrm{Cu}$ and proteins like the amyloid precursor protein (APP), the prion protein $(\operatorname{PrP}), \alpha$-synuclein $(\alpha$-syn) or neurotrophic factors. Interestingly, $\operatorname{PrP}$ proteins seem to be target genes of MTF-1 (Grzywacz et al., 2015). Moreover, Cu levels are altered in brains of patients suffering from AD, Huntington's Disease (HD) and $\mathrm{PD}$. In $\mathrm{AD}$ and $\mathrm{PD}, \mathrm{Cu}$ levels are overall reduced but enriched in the amyloid plaques, whereas $\mathrm{Cu}$ accumulates in HD brains (Fox et al., 2007; Davies et al., 2016; McAllum and Finkelstein, 2016). Cu binds directly bind to $\alpha$-syn and promotes the formation of toxic oligomers (Davies et al., 2016). Similarly, $\mathrm{Cu}$ has also been found to facilitate amyloid beta $(\mathrm{A} \beta)$ deposition, formation of tau fibrills (McAllum and Finkelstein, 2016) as well as aggregation of Huntingtin ( $\mathrm{Htt})$ containing aberrant polyQ expansions (Fox et al., 2007). All these evidences and many more (Opazo et al., 2014; D’Ambrosi and Rossi, 2015) reveal new connections between $\mathrm{Cu}$ and neurodegenerative diseases. The critical role of $\mathrm{Cu}$ in several neurodevelopmental, neuromuscular and neurodegenerative disorders has been recently corroborated with the characterization of the cellular interactome of human ATP7A (Comstra et al., 2017). Similarly, $\mathrm{Zn}$ is also concentrated in glutamatergic synaptic terminals where it interacts with neurotransmitter receptors to modulate synaptic activity (Sensi et al., 2009, 2011). Although evidences about $\mathrm{Zn}$ levels in AD brains are contradictory, $\mathrm{Zn}$ metabolism is clearly disturbed in $\mathrm{AD}$ and several studies have demonstrated that $\mathrm{Zn}$ is crucial in the olimerization of $A \beta$. Furthermore, it has been suggested that combination of $\mathrm{Cu}$ and $\mathrm{Zn}$ dyshomeostasis increased toxicity of A $\beta$ (Sensi et al., 2011; McAllum and Finkelstein, 2016). Mutations in ATP13A2 (PARK9) have been associated to PD. ATP13A2 encodes a $\mathrm{P} 5 \mathrm{~B}$-type ATPase and although its specific substrate is still not clear, some evidences point toward $\mathrm{Zn}$ as a very good candidate (Tsunemi and Krainc, 2014).

\section{Cu-Related Diseases}

Menkes disease (MD) is the most important and best characterized neurological disorder related to $\mathrm{Cu}$ homeostasis. $\mathrm{MD}$ is a pediatric fatal metabolic syndrome accompanied with neurodevelopmental and neurodegenerative defects with a prevalence of 1:50,000 individuals (de Bie et al., 2007). MD is a recessive disorder produced by a loss of function of ATP7A. In the last 50 years, more than 370 mutations affecting ATP7A have been described. Depending on the severity of the symptoms, they have been ascribed, to different types of $\mathrm{X}$ linked disorders named classical MD, occipital horn syndrome and spinal muscular atrophy (Zlatic et al., 2015). However, the mechanism of neurodegeneration is still poorly understood. Impairment of ATP7A functions induces accumulation of $\mathrm{Cu}$ into intestinal enterocytes but a deficiency of $\mathrm{Cu}$ in plasma, kidney, neurons and astrocytes due to the lack of transport of $\mathrm{Cu}$ into these tissues (Kaler, 2011). Mutations in ATP7A triggers several neurological phenotypes such as abnormal neuroblast migration, atrophy of gray and white matter as well as loss of neurons in the brain cortex and aberrant dendritic arborizations (Zlatic et al., 2015). The so called "oligoenzymatic hypothesis" (lack of $\mathrm{Cu}$ in cuproenzymes) does not explain the constellation of neurological manifestations and therefore, other proteins must be involved, too. In this sense, the existing mouse models very nicely recapitulate the human physiological and cellular defects (Lenartowicz et al., 2015) but they have failed to unveil new elements of the pathogenic mechanism. Moreover, it is still a matter of debate whether neurodegeneration in Menkes is a consequence of loss of ATP7A in neurons or of nutritional $\mathrm{Cu}$. The potential of the fly will be very helpful to address particular roles of $\mathrm{Cu}$ in neurological disorders as well as to unveil novel neuronal specific proteins involved in $\mathrm{Cu}$ homeostasis and in the pathogenesis of MD.

As stated above, DmATP7 is the fly ortholog of ATP7A (Southon et al., 2004). Remarkably, null alleles of DmATP7 resemble human MD phenotypes (Norgate et al., 2006) and DmATP7 is able to restore normal copper levels in MD patient's fibroblasts (Southon et al., 2010). All this shows a clear functional homology between human and fly proteins. Analysis of mutants shows that DmATP7 is essential in early development as mutants never reach third instar larvae. Mutant larvae also display hypopigmentation (due to lack of Tyr activity) and lethargic behavior (because of compromised synthesis of neurotransmitters). Therefore, DmATP7 plays a dual role 
exporting $\mathrm{Cu}$ from the cells and delivering it to cuproenzymes (Norgate et al., 2006). Silencing of DmATP7 in the fly digestive tract is sufficient to induce $\mathrm{Cu}$ retention in the gut (Binks et al., 2010) and to reduce $\mathrm{Cu}$ content in the nervous system. This systemic effect triggers, in turn, neurodevelopmental Menkeslike phenotypes such as enhanced pupal lethality and smaller brain size (Bahadorani et al., 2010a). However, the small proportion of adults that successfully completed development show normal lifespan, but with hypersensitivity to oxidative insult (Bahadorani et al., 2010a) likely because lack of a functional antioxidant enzyme $\mathrm{Cu} / \mathrm{ZnSOD}$. Reduction of DmATP7 in different neuropeptidergic neurons had a strong impact on amidation of several neuropeptides but effects on fly behavior were more limited than anticipated (Sellami et al., 2012). DmATP7 has recently been shown to interact with the oligomeric Golgi complex (COG) to control the development of synapsis via a novel mechanism (Comstra et al., 2017). All these results indicate that DmATP7 plays cell and non-autonomous roles in $\mathrm{Cu}$ homeostasis. Moreover, survival of flies lacking $D m A T P 7$ is improved by increasing $\mathrm{Cu}$ content in the food and by upregulating $d M T F-1$. This will consequently promote expression of $C \operatorname{tr} 1 B$ to potentiate supply of $\mathrm{Cu}$ and of Mtns to reduce toxic effects of $\mathrm{Cu}$ accumulation in the gut (Bahadorani et al., 2010a). It is important to highlight that Drosophila only contains one ATP7 ortholog and therefore the fruit fly might also be an interesting organism to model Wilson's disease (WD), a human disorder caused by mutations in the ATP7B gene which produces increased intracellular $\mathrm{Cu}$ levels, accumulation of ROS, mitochondrial dysfunction and cell death (Bandmann et al., 2015). The fly models of MD and WD have gone one step beyond since they are being used as diagnostic tools to establish the pathogenicity of variants found in patients. The ability of given variants to improve the larval lethality of the fly null mutant helps to discriminate between pathological and control-like variants. In addition, subcellular localization of mutant forms have provided insight into the mechanism of copper dyshomeostasis in MD and WD patients (Mercer et al., 2017).

Several other neurodegenerative disorders have been shown to have an intimate relation with $\mathrm{Cu}$ (Ayton et al., 2013; McAllum and Finkelstein, 2016), although it is not clear if $\mathrm{Cu}$ is a friend or a foe. Usually WD patients manifest Parkinson-like symptoms (Bandmann et al., 2015). Therefore, it would be interesting to test the influence of $\mathrm{Cu}$ in PD models and whether manipulation of cellular $\mathrm{Cu}$ content might have a beneficial effect (Table 1). From the whole plethora of fly models (Botella et al., 2009), this has only been addressed in flies deficient for the protein Parkin (Saini et al., 2010). In this work, Cu-specific chelation by means of BCS was sufficient to increase longevity of parkin null mutants. Additional evidences suggested that reduction of ROS was mediating the neuroprotective effect of BCS in parkin deficient flies (Saini et al., 2010). It is likely that the combination of redox-activity of free $\mathrm{Cu}$ and the mitochondrial dysfunction in parkin mutant flies boosted the generation of ROS in these flies. The $\mathrm{Cu}$-parkin relation was further corroborated by genetic interactions. Indeed, loss of parkin exacerbated the retinal degeneration triggered by overexpression of the $\mathrm{Cu}$ importer Ctr1B (Hua et al., 2010). Cu levels have been demonstrated to be lower in PD patients (Davies et al., 2016) although the rescue with BCS from Saini and collaborators goes in an opposite direction. Therefore, it would be of high relevance for the scientific community to study the impact of $\mathrm{Cu}$ biology in other PD fly models.

Modulation of $\mathrm{Cu}$ metabolism has also successfully improved the deleterious defects of toxic A $\beta 42$ peptides in Drosophila models of AD (Lang et al., 2013; Singh et al., 2013; Table 1). A $\beta$ proteins are the major component of plaques in $\mathrm{AD}$ patients. The $\mathrm{A} \beta 42$ isoform is more prone to aggregation due to the 2 extra aminoacids at the C-terminus (White et al., 1999). Reduction of cellular $\mathrm{Cu}$ content by silencing the expression of $\operatorname{Ctr} 1 B$ and Ctr1C (Lang et al., 2013), by overexpressing DmATP7 (Lang et al., 2013) and dMTF-1 or MtnA (Hua et al., 2011b) improved neurodegeneration, locomotion, longevity and oxidative stress markers. Similar effects were obtained by chemical chelation of $\mathrm{Cu}$ (Hua et al., 2011b; Singh et al., 2013). On the contrary, increasing cellular $\mathrm{Cu}$ or impairing intracellular $\mathrm{Cu}$ delivery worsened the phenotypes (SanokawaAkakura et al., 2010; Hua et al., 2011b). The work from Lang and collaborators raised a couple of interesting and paradoxical questions. First, AD phenotypes are rescued by panneuronal silencing of $C \operatorname{tr} 1 B$ and $C$, genes supposed to be only expressed in fly gut and male gonads (Zhou et al., 2003; Hua et al., 2010). This indicates that better reporters to study expression patterns of these genes are needed. Second, the improvements were accompanied by increased amounts of higher-molecular weight forms of $A \beta 42$. This result clearly questions the toxicity of the aggregates. However, similar genetic interventions in a fly model of HD expressing the mutant form of Htt (expanded polyQ tract) successfully reduced the levels of PolyQ aggregation by decreasing $\mathrm{Cu}$ content in flies (Xiao et al., 2013). Therefore, $\mathrm{Cu}$ metabolism might exert different and even opposite roles in distinct disease models. As a consequence, locomotion, survival and brain degeneration were also improved in this HD fly model (Xiao et al., 2013). These experiments revealed that $\mathrm{Cu}$ facilitates protein aggregation in HD. In agreement, a mutant form of $\mathrm{Htt}$ unable to bind $\mathrm{Cu}$ displayed a reduced toxicity (Xiao et al., 2013).

Other reports in the fly have identified genes with influence on neurodegenerative or neuropsychiatric diseases that resulted in new actors of $\mathrm{Cu}$ metabolism. Presenilins participate in the processing of $A \beta$ proteins as they are the catalytic unit of the $\gamma$-secretase complex and their mutations underlie the majority of early-onset AD cases. Interestingly, secretase-independent roles have been reported for presenilins (Stiller et al., 2014). Silencing of PSN, the presenilin ortholog present in flies, in the fly gut reduced copper levels in flies and increased tolerance to excess dietary copper but also susceptibility to oxidative insult. PSN is suggested to contribute to the localization of $\mathrm{Cu}$ importers Ctr1 A and Ctr1B in the plasma membrane (Southon et al., 2013b) but the exact action mechanism still needs to be completely elucidated. Misexpression of high molecular weight immunophilin FKBP52, which is a known interactor of the $\mathrm{Cu}$ chaperone Atox1, also modulates toxicity of A 42 (SanokawaAkakura et al., 2010). Finally, disruption of the dysbindin/BLOC1 complex in the fly by means of Drosophila BLOC-1 mutants 
is sufficient to alter $\mathrm{Cu}$ metabolism suggesting that external factors might modulate schizophrenia via mechanisms that are conserved from humans to flies (Gokhale et al., 2015).

\section{Zn-Related Diseases}

$\mathrm{Zn}$ also needs to be tightly regulated because excess or deprivation of $\mathrm{Zn}$ has severe health effects. Many reviews summarize the toxic consequences of $\mathrm{Zn}$ dyshomeostasis in humans and murine models (Fukada and Kambe, 2011; Hagmeyer et al., 2014; Kambe et al., 2014, 2015; Terrin et al., 2015). For example, $\mathrm{Zn}$ deficiency in the fetus affects organ growth that can result into preterm birth or even early death (Terrin et al., 2015). In mouse models, several behavioral tests have linked $\mathrm{Zn}$ deficiency with deficits in learning and memory or increased anxiety or depression-like disorders (Hagmeyer et al., 2014). Zn homeostasis is a pretty new field in the fly and although several new tools are being continuously implemented to further characterize the Drosophila $\mathrm{Zn}$ transporters, there are not many fly models of $\mathrm{Zn}$-dependent diseases. In humans, mutations or even Single Nucleotide Polymorphisms (SNPs) in $\mathrm{ZnT}$ or Zip genes have been already associated to particular diseases (Fukada and Kambe, 2011; Kambe et al., 2015). For example, mutations in $\mathrm{ZnT} 10$ are responsible for hepatic cirrhosis that is accompanied with Parkinsonism or mutations in Zip4 triggers Acrodermatitis enteropathica. On the other hand, SNPs in ZnT8 are linked with increased susceptibility toward type I and II diabetes mellitus. From all human disorders directly related to $\mathrm{Zn}$ homeostasis, the Spondylocheirodysplasia-EhlersDanlos Syndrome-Like is the only one modeled in Drosophila (Xiao et al., 2014). The Ehlers-Danlos Syndrome is produced by loss of function of the human Zip13 transporter. However, the Drosophila ortholog dZip99C (CG7816) is involved in iron efflux and not in $\mathrm{Zn}$ transport. Loss of $d Z i p 99 \mathrm{C}$ affects iron storage by ferritin, increases cytosolic iron and, in agreement with the human counterpart, reduces collagen production. Interestingly, the fact that hZip13 but not hZip7 (a closely related gene that has been shown to import $\mathrm{Zn}$ ) can complement $d Z i p 99 C$ (Xiao et al., 2014), might suggest that the human disorder is also triggered by iron deregulation and thus, $\mathrm{Zn}$ defects are a secondary event.

Manipulation of $\mathrm{Zn}$ regulatory network has been a very successful approach to ameliorate neuronal dysfunction in Drosophila models of $\mathrm{AD}$ as well as to decipher the functional roles of $\mathrm{Zn}$ in this disease (Table 2). In an AD model based on overexpression of a mutant version of human Tau, results from a genetic screening showed that increasing or reducing the expression of a $d Z i p 42 C .1$ and $d Z n T 63 C$ successfully modified Tau-related phenotypes in the fly (Huang et al., 2014). Reduction of $\mathrm{Zn}$ content by $d Z n T 63 C$ overexpression, silencing of $d Z i p 42 C .1$ or chemical chelation improved longevity, brain vacuolization and retinal degeneration. Remarkably, authors proved in the fly that Tau phosphorylation was mediated by $\mathrm{Zn}$ and that hyperphosphorylation was a cardinal mechanism underlying toxicity. Furthermore, as $\mathrm{Zn}$ can directly bind Tau protein, authors mutated specific residues to suppress this interaction. This was sufficient to reduce Tau toxicity by suppressing Tau aggregation but without changing Tau phosphorylation. Thus, this work showed in vivo two $\mathrm{Zn}$-dependent mechanisms underpinning Tau toxicity (Huang et al., 2014). In a second AD model, $\mathrm{Zn}$ chelation was sufficient to improve longevity, locomotion and photoreceptor degeneration in flies overexpressing $\mathrm{A} \beta 42$ protein. As expected, $\mathrm{Zn}$ supplementation exacerbated the phenotypes. This enhancement was suppressed in a special variant of A $\beta 42$ in which Zn binding was abolished (Hua et al., 2011b). In agreement with the critical role of $\mathrm{Zn}$ metabolism in this model, other authors found that $d Z i p 42 C .1$ level increases with age in the brain of $A \beta 42$-expressing flies, whereas it goes down in controls. Such levels explain the accumulation of $\mathrm{Zn}$ in the brain of A 442 (Lang et al., 2012) and the toxic effects of $\mathrm{Zn}$ supplementation (Hua et al., 2011b). In line with these evidences, $\mathrm{KD}$ of $d Z i p 42 C .1$ was sufficient to reduce neurodegeneration, prolong lifespan and improve memory loss as well as A $\beta 42$ deposits in transgenic flies (Lang et al., 2012). All these results suggest that $d Z i p 42 C .1$ is critically involved in the pathology of $\mathrm{A} \beta 42$. Paradoxically, overexpression of $d Z i p 42 C .1$ also resulted in obvious memory recovery but the mechanism was not described in the manuscript.

Similar contradictory findings have been recently described in a Drosophila model of Friedreich's ataxia (FRDA). FRDA is the most important recessive ataxia in the Caucasian population. Impairment of transcription of the gene frataxin is the molecular cause underlying the disease (Campuzano et al., 1996). Most of the current evidences support a strong relation between frataxin and iron in several models (Kakhlon et al., 2008; Huang et al., 2009; Schmucker et al., 2011), including the fly (Soriano et al., 2013; Navarro et al., 2015; Chen et al., 2016). Moreover, genetic and chemical manipulation of iron biology was found to have a positive impact in FRDA phenotypes (Kakhlon et al., 2008; Whitnall et al., 2008; Navarro et al., 2015). Remarkably, flies displaying reduced levels of frataxin also seemed to have altered levels of other metals such as $\mathrm{Zn}$ and $\mathrm{Cu}$. Although the contribution of other metals was already suggested by studies in human samples (Koeppen et al., 2012, 2013), this fly work was the first one showing that therapies based on such metals might be beneficial (Soriano et al., 2016). Indeed, $\mathrm{Zn}$ and $\mathrm{Cu}$ chelators improved frataxin deficiency without altering iron content. In this line, silencing either $d Z i p 42 C .1, d Z i p 42 C .2$ and $d Z i p 88 E$ or $d Z n T 35 C, d Z n T 41 F$ and $d Z n T 63 C$ also improved FRDA conditions via reduction of the iron content (Table 2). All these results raise several interesting questions: Why are $\mathrm{Cu}$ and $\mathrm{Zn}$ accumulating in FRDA flies? Why does KD of genes with opposite function or acting in different cellular compartments trigger the same effect? Did they also modify the accumulation of $\mathrm{Zn}$ in FRDA flies? Is it possible that any of these transporters has also a mitochondrial function?

Studies of a Drosophila PD model took advantage of the antioxidant properties of $\mathrm{Zn}$ and explored the possibility to counteract the increased oxidative stress in the fly parkin mutant (Greene et al., 2005) by Zn supplementation. Interestingly, parkin mutant flies displayed altered levels of several $\mathrm{Zn}$ transporters such as $d Z n T 35 C, d Z n T 63 C$, or foi and had reduced Zn content in the head. Importantly, dietary Zn successfully increased eclosion frequency, survival rate and head zinc content of parkin mutants (Saini and Schaffner, 2010). Results showed that Zn boosted 
expression of Mtns and that the ROS scavenging properties of Mtns mediated the rescue mechanism. In relation to PD, Catsup mutants, surprisingly, have increased tolerance against paraquat induced neurotoxicity (Chaudhuri et al., 2007). This result is interesting since Catsup mutants display high tyrosine hydroxylase $(\mathrm{TH})$ activity and therefore increased dopamine pools (Stathakis et al., 1999), whereas reduction of $T H$ expression and dopamine levels rescued PD phenotypes in two other fly models of the disease (Bayersdorfer et al., 2010). Although the mechanism driven by loss of Catsup was not addressed in the manuscript, we can speculate that the activation of stress pathways in the mutants (Groth et al., 2013) might contribute to counteract the paraquat effect.

In the literature, the relation between $\mathrm{Zn}$ and fly models of human diseases is mostly based on studies about neurodegenerative disorders (Table 2). Importantly, the fly has also been useful to mimic other human diseases and expand their knowledge beyond the state of the art. A recent report showed that $\mathrm{Zn}$ is also a crucial mediator in the formation of urinary stones. In human, deficiency of xanthine dehydrogenase is responsible of such kidney stones (Arikyants et al., 2007). In the fly, silencing of the ortholog gene ( $X d h$ also known as $r y$, CG7642) also induces the presence of small stones in the intraluminal content of Malpighian tubules. Spectrometric analysis of such stones revealed high similarity to the human ones including the presence of abundant $\mathrm{Zn}$. In line with this novel perspective, reduction of the expression of three $\mathrm{ZnT}$ transporters ( $d Z n T 35 C, d Z n T 41 F, d Z n T 63 C)$ and of $d Z i p 71 B$ that are highly expressed in the Malpighian tubules mitigated the formation of stones as well as other phenotypes associated to loss of $X d h$ (Chi et al., 2015; Yin et al., 2017). Evidences suggest that downregulation of these genes avoid the accumulation of $\mathrm{Zn}$ in the lumen of the tubules. In agreement, $\mathrm{Zn}$ chelation by N,N,N'N'-tetrakis- (2-pyridylmethyl)ethylenediamine (TPEN) also lead to similar results (Chi et al., 2015). A link between cancer and $\mathrm{Zn}$ has been established throughout the processing of the morphogen hedgehog $(h h)$. $\mathrm{Zn}$ normally inhibits fly $\mathrm{hh}$ autoprocessing and thus upon $\mathrm{Zn}$ deficiency there is an overactivation of the pathway that might contribute to pathogenesis of several cancer types (Xie et al., 2015).

\section{THE POTENTIAL OF DROSOPHILA FOR FUTURE STUDIES}

However, there are some aspects of $\mathrm{Cu}$ and $\mathrm{Zn}$ biology that still remain obscure. For example, it is of paramount importance to understand the need of so many ZnTs and Zips to regulate $\mathrm{Zn}$ metabolism. The number of genes performing similar functions confers an unexpected level of complexity. Furthermore, establishing the precise spatial and temporal expression pattern

\section{REFERENCES}

Afshar, N., Argunhan, B., Bettedi, L., Szular, J., and Missirlis, F. (2013). A recessive $\mathrm{X}$-linked mutation causes a threefold reduction of total body zinc accumulation in Drosophila melanogaster laboratory strains. FEBS Open Bio. 3, 302-304. doi: 10.1016/j.fob.2013.07.003 of each gene regulating $\mathrm{Cu}$ and $\mathrm{Zn}$ homeostasis will facilitate the interpretation of many aspects of the metal biology. Frank Schnorrer's and Hugo Bellen's labs have created two large-scale transgenic collections that allow protein visualization. The first one is based on a fosmid library of clones in which target genes are C-terminally tagged within their genomic context (Sarov et al., 2016). The second one has modified the Minos mediated integration cassette (MiMIC) to introduce a dominant marker and a gene-trap cassette flanked by two inverted ФC31 attP sites (Venken et al., 2011). The MiMIC collection also allows the replacement of the gene-trap cassette via recombinase mediated cassette exchange (RMCE) even without the need of microinjection (Nagarkar-Jaiswal et al., 2015a,b). A similar approach combining CRISPR and RMCE has been reported (Zhang et al., 2014). The labs of Christopher Potter, Matthias Landgraf and Benjamin White have very nicely mixed both, MiMIC, and CRISPR, strategies and have generated another collection of so called Trojan-GAL4 lines (Diao et al., 2015). This strategy takes advantage of MiMIC transposons located in introns between coding exons and exchanges their content with a T2A-GAL4 cassette. Because of it, the native gene product will be cleaved and translation of GAL4 will occur as an independent protein. A perfect complement to these reporters in the possibility to perform cell-type-specific transcriptional profiling without cell isolation (Southall et al., 2013; Marshall et al., 2016). This extremely powerful tool developed in Andrea Brand's lab might help to clarify the cells/tissues expressing the different $\mathrm{Zn}$ and $\mathrm{Cu}$ transporters.

$\mathrm{Up}$ to now, tissue-specific analysis of $\mathrm{Cu}$ and $\mathrm{Zn}$ relies on RNAi lines. However, they are not completely effective and the residual gene activity might be sufficient to hide some important aspects of gene function. To bypass this, Simon Bullock's lab has developed a fast approach to generate CRISPR mutants by means of the UAS/GAL4 system (Port and Bullock, 2016). Finally, the possibility to perform unbiased genetic screens, which confers Drosophila an important advantage over other higher eukaryotic model systems, will allow to identify new genetic factors involved in the regulatory networks of $\mathrm{Cu}$ and $\mathrm{Zn}$ and modifiers of phenotypes in the fly models of human diseases.

\section{AUTHOR CONTRIBUTIONS}

JAN and SS designed, wrote and approved the final manuscript.

\section{ACKNOWLEDGMENTS}

JAN and SS thank Olga Rivero for critically reading the manuscript and Maribel Calabuig and Ursula Roth for helping with the Art Work and figure preparation.

Al-Momani, F. A., and Massadeh, A. M. (2005). Effect of different heavy-metal concentrations on Drosophila melanogaster larval growth and development. Biol. Trace Elem. Res. 108, 271-277. doi: 10.1385/BTER:108:1-3:271

Arikyants, N., Sarkissian, A., Hesse, A., Eggermann, T., Leumann, E., and Steinmann, B. (2007). Xanthinuria type I: a rare cause of urolithiasis. Pediatr. Nephrol. 22, 310-314. doi: 10.1007/s00467-006-0267-3 
Atanesyan, L., Günther, V., Celniker, S. E., Georgiev, O., and Schaffner, W. (2011). Characterization of MtnE, the fifth metallothionein member in Drosophila. J. Biol. Inorg. Chem. 16, 1047-1056. doi: 10.1007/s00775-011-0825-4

Ayton, S., Lei, P., and Bush, A. I. (2013). Metallostasis in Alzheimer's disease. Free Radic. Biol. Med. 62, 76-89. doi: 10.1016/j.freeradbiomed.2012.10.558

Bahadorani, S., Bahadorani, P., Marcon, E., Walker, D. W., and Hilliker, A. J. (2010a). A Drosophila model of Menkes disease reveals a role for DmATP7 in copper absorption and neurodevelopment. Dis. Model. Mech. 3, 84-91. doi: $10.1242 / \mathrm{dmm} .002642$

Bahadorani, S., Mukai, S., Egli, D., and Hilliker, A. J. (2010b). Overexpression of metal-responsive transcription factor (MTF-1) in Drosophila melanogaster ameliorates life-span reductions associated with oxidative stress and metal toxicity. Neurobiol. Aging 31, 1215-1226. doi: 10.1016/j.neurobiolaging.2008.08.001

Balamurugan, K., Egli, D., Hua, H., Rajaram, R., Seisenbacher, G., Georgiev, O., et al. (2007). Copper homeostasis in Drosophila by complex interplay of import, storage and behavioral avoidance. ЕMBO J. 26, 1035-1044. doi: 10.1038/sj.emboj.7601543

Balamurugan, K., Egli, D., Selvaraj, A., Zhang, B., Georgiev, O., and Schaffner, W. (2004). Metal-responsive transcription factor (MTF-1) and heavy metal stress response in Drosophila and mammalian cells: a functional comparison. Biol. Chem. 385, 597-603. doi: 10.1515/BC.2004.074

Balamurugan, K., Hua, H., Georgiev, O., and Schaffner, W. (2009). Mercury and cadmium trigger expression of the copper importer Ctr1B, which enables Drosophila to thrive on heavy metal-loaded food. Biol. Chem. 390, 109-113. doi: 10.1515/BC.2009.020

Bandmann, O., Weiss, K. H., and Kaler, S. G. (2015). Wilson's disease and other neurological copper disorders. Lancet Neurol. 14, 103-113. doi: 10.1016/S1474-4422(14)70190-5

Bargiello, T. A., and Young, M. W. (1984). Molecular genetics of a biological clock in Drosophila. Proc. Natl. Acad. Sci. U.S.A. 81, 2142-2146. doi: 10.1073/pnas.81.7.2142

Bassett, A. R., and Liu, J.-L. (2014). CRISPR/Cas9 and genome editing in Drosophila. J. Genet Genomics 41, 7-19. doi: 10.1016/j.jgg.2013.12.004

Bayersdorfer, F., Voigt, A., Schneuwly, S., and Botella, J. A. (2010). Dopaminedependent neurodegeneration in Drosophila models of familial and sporadic Parkinson's disease. Neurobiol. Dis. 40, 113-119. doi: 10.1016/j.nbd.2010.02.012

Binks, T., Lye, J. C., Camakaris, J., and Burke, R. (2010). Tissue-specific interplay between copper uptake and efflux in Drosophila. J. Biol. Inorg. Chem. 15, 621-628. doi: 10.1007/s00775-010-0629-y

Bonilla-Ramirez, L., Jimenez-Del-Rio, M., and Velez-Pardo, C. (2011). Acute and chronic metal exposure impairs locomotion activity in Drosophila melanogaster: a model to study Parkinsonism. Biometals 24, 1045-1057. doi: 10.1007/s10534-011-9463-0

Bonneton, F., Théodore, L., Silar, P., Maroni, G., and Wegnez, M. (1996). Response of Drosophila metallothionein promoters to metallic, heat shock and oxidative stresses. FEBS Lett. 380, 33-38. doi: 10.1016/0014-5793(95)01544-2

Botella, J. A., Bayersdorfer, F., Gmeiner, F., and Schneuwly, S. (2009). Modelling Parkinson's disease in Drosophila. Neuromolecular Med. 11, 268-280. doi: 10.1007/s12017-009-8098-6

Bouleau, S., and Tricoire, H. (2015). Drosophila models of Alzheimer's disease: advances, limits, and perspectives. J. Alzheimers Dis. 45, 1015-1038. doi: 10.3233/JAD-142802

Brand, A. H., and Perrimon, N. (1993). Targeted gene expression as a means of altering cell fates and generating dominant phenotypes. Development 118, 401-415.

Burke, R., Commons, E., and Camakaris, J. (2008). Expression and localisation of the essential copper transporter DmATP7 in Drosophila neuronal and intestinal tissues. Int. J. Biochem. Cell Biol. 40, 1850-1860. doi: 10.1016/j.biocel.2008.01.021

Calap-Quintana, P., González-Fernández, J., Sebastiá-Ortega, N., Llorens, J. V., and Moltó, M. D. (2017). Drosophila melanogaster models of metalrelated human diseases and metal toxicity. Int. J. Mol. Sci. 18:E1456. doi: $10.3390 /$ ijms 18071456

Campuzano, V., Montermini, L., Moltò, M. D., Pianese, L., Cossée, M., Cavalcanti, F., et al. (1996). Friedreich's ataxia: autosomal recessive disease caused by an intronic GAA triplet repeat expansion. Science 271, 1423-1427. doi: $10.1126 /$ science.271.5254.1423
Carrasco-Rando, M., Atienza-Manuel, A., Martín, P., Burke, R., and Ruiz-Gómez, M. (2016). Fear-of-intimacy-mediated zinc transport controls the function of zinc-finger transcription factors involved in myogenesis. Development 143 , 1948-1957. doi: 10.1242/dev.131953

Casci, I., and Pandey, U. B. (2015). A fruitful endeavor: modeling ALS in the fruit fly. Brain Res. 1607, 47-74. doi: 10.1016/j.brainres.2014.09.064

Chandra, S., Pandey, A., and Chowdhuri, D. K. (2015). MiRNA profiling provides insights on adverse effects of $\mathrm{Cr}(\mathrm{VI})$ in the midgut tissues of Drosophila melanogaster. J. Hazard. Mater. 283, 558-567. doi: 10.1016/j.jhazmat.2014.09.054

Chaudhuri, A., Bowling, K., Funderburk, C., Lawal, H., Inamdar, A., Wang, Z., et al. (2007). Interaction of genetic and environmental factors in a Drosophila parkinsonism model. J. Neurosci. 27, 2457-2467. doi: 10.1523/JNEUROSCI.4239-06.2007

Chen, K., Lin, G., Haelterman, N. A., Ho, T. S., Li, T., Li, Z., et al. (2016). Loss of Frataxin induces iron toxicity, sphingolipid synthesis, and Pdk1/Mef2 activation, leading to neurodegeneration. ELife 5:e16043. doi: $10.7554 /$ eLife. 16043

Chen, X., Hua, H., Balamurugan, K., Kong, X., Zhang, L., George, G. N., et al. (2008). Copper sensing function of Drosophila metal-responsive transcription factor-1 is mediated by a tetranuclear $\mathrm{Cu}(\mathrm{I})$ cluster. Nucleic Acids Res. 36, 3128-3138. doi: 10.1093/nar/gkn103

Chi, T., Kim, M. S., Lang, S., Bose, N., Kahn, A., Flechner, L., et al. (2015). A Drosophila model identifies a critical role for zinc in mineralization for kidney stone disease. PLoS ONE 10:e0124150. doi: 10.1371/journal.pone.0124150

Choi, S., and Bird, A. J. (2014). Zinc'ing sensibly: controlling zinc homeostasis at the transcriptional level. Metallomics 6, 1198-1215. doi: 10.1039/c4mt00064a

Clark, I. E., Dodson, M. W., Jiang, C., Cao, J. H., Huh, J. R., Seol, J. H., et al. (2006). Drosophila pink1 is required for mitochondrial function and interacts genetically with parkin. Nature 441, 1162-1166. doi: 10.1038/nature04779

Comstra, H. S., McArthy, J., Rudin-Rush, S., Hartwig, C., Gokhale, A., Zlatic, S. A., et al. (2017). The interactome of the copper transporter ATP7A belongs to a network of neurodevelopmental and neurodegeneration factors. ELife 6:e24722. doi: 10.7554/eLife.24722

D'Ambrosi, N., and Rossi, L. (2015). Copper at synapse: release, binding and modulation of neurotransmission. Neurochem. Int. 90, 36-45. doi: 10.1016/j.neuint.2015.07.006

de Bie, P., Muller, P., Wijmenga, C., and Klomp, L. W. (2007). Molecular pathogenesis of Wilson and Menkes disease: correlation of mutations with molecular defects and disease phenotypes. J. Med. Genet. 44, 673-688. doi: $10.1136 / \mathrm{jmg} .2007 .052746$

Davies, K. M., Mercer, J. F. B., Chen, N., and Double, K. L. (2016). Copper dyshomoeostasis in Parkinson's disease: implications for pathogenesis and indications for novel therapeutics. Clin. Sci. (Lond) 130, 565-574. doi: $10.1042 / C S 20150153$

Dechen, K., Richards, C. D., Lye, J. C., Hwang, J. E. C., and Burke, R. (2015). Compartmentalized zinc deficiency and toxicities caused by ZnT and Zip gene over expression result in specific phenotypes in Drosophila. Int. J. Biochem. Cell Biol. 60, 23-33. doi: 10.1016/j.biocel.2014.12.017

Diao, F., Ironfield, H., Luan, H., Diao, F., Shropshire, W. C., Ewer, J., et al. (2015). Plug-and-play genetic access to Drosophila cell types using exchangeable exon cassettes. Cell Rep. 10, 1410-1421. doi: 10.1016/j.celrep.2015.01.059

Dietzl, G., Chen, D., Schnorrer, F., Su, K.-C., Barinova, Y., Fellner, M., et al. (2007). A genome-wide transgenic RNAi library for conditional gene inactivation in Drosophila. Nature 448, 151-156. doi: 10.1038/nature05954

Duffy, J. B. (2002). GAL4 system in Drosophila: a fly geneticist's Swiss army knife. Genesis 34, 1-15. doi: 10.1002/gene.10150

Durliat, M., Bonneton, F., Boissonneau, E., André, M., and Wegnez, M. (1995). Expression of metallothionein genes during the post-embryonic development of Drosophila melanogaster. Biometals 8, 339-351. doi: 10.1007/BF00141608

Egli, D., Domènech, J., Selvaraj, A., Balamurugan, K., Hua, H., Capdevila, M., et al. (2006a). The four members of the Drosophila metallothionein family exhibit distinct yet overlapping roles in heavy metal homeostasis and detoxification. Genes Cells 11, 647-658. doi: 10.1111/j.1365-2443.2006.00971.x

Egli, D., Selvaraj, A., Yepiskoposyan, H., Zhang, B., Hafen, E., Georgiev, O., et al. (2003). Knockout of 'metal-responsive transcription factor' MTF-1 in Drosophila by homologous recombination reveals its central role in heavy metal homeostasis. EMBO J. 22, 100-108. doi: 10.1093/emboj/cdg012 
Egli, D., Yepiskoposyan, H., Selvaraj, A., Balamurugan, K., Rajaram, R., Simons, A., et al. (2006b). A family knockout of all four Drosophila metallothioneins reveals a central role in copper homeostasis and detoxification. Mol. Cell. Biol. 26, 2286-2296. doi: 10.1128/MCB.26.6.2286-2296.2006

Esposito, G., Vos, M., Vilain, S., Swerts, J., De Sousa Valadas, J., van Meensel, S., et al. (2013). Aconitase causes iron toxicity in Drosophila pink1 mutants. PLoS Genet. 9:e1003478. doi: 10.1371/journal.pgen.1003478

Feany, M. B., and Bender, W. W. (2000). A Drosophila model of Parkinson's disease. Nature 404, 394-398. doi: 10.1038/35006074

Folwell, J. L., Barton, C. H., and Shepherd, D. (2006). Immunolocalisation of the D. melanogaster Nramp homologue Malvolio to gut and Malpighian tubules provides evidence that Malvolio and Nramp2 are orthologous. J. Exp. Biol. 209, 1988-1995. doi: 10.1242/jeb.02193

Fox, J. H., Kama, J. A., Lieberman, G., Chopra, R., Dorsey, K., Chopra, V., et al. (2007). Mechanisms of copper ion mediated Huntington's disease progression. PLoS ONE 2:e334. doi: 10.1371/journal.pone.0000334

Fukada, T., and Kambe, T. (2011). Molecular and genetic features of zinc transporters in physiology and pathogenesis. Metallomics 3, 662-674. doi: $10.1039 / \mathrm{clmt} 00011 \mathrm{j}$

Georgiev, P., Okkenhaug, H., Drews, A., Wright, D., Lambert, S., Flick, M., et al. (2010). TRPM channels mediate zinc homeostasis and cellular growth during Drosophila larval development. Cell Metab. 12, 386-397. doi: 10.1016/j.cmet.2010.08.012

Gokhale, A., Vrailas-Mortimer, A., Larimore, J., Comstra, H. S., Zlatic, S. A., Werner, E., et al. (2015). Neuronal copper homeostasis susceptibility by genetic defects in dysbindin, a schizophrenia susceptibility factor. Hum. Mol. Genet. 24, 5512-5523. doi: $10.1093 / \mathrm{hmg} / \mathrm{ddv} 282$

Golic, K. G. (1991). Site-specific recombination between homologous chromosomes in Drosophila. Science 252, 958-961. doi: 10.1126/science.2035025

Graveley, B. R., Brooks, A. N., Carlson, J. W., Duff, M. O., Landolin, J. M., Yang, L., et al. (2011). The developmental transcriptome of Drosophila melanogaster. Nature 471, 473-479. doi: 10.1038/nature09715

Greene, J. C., Whitworth, A. J., Andrews, L. A., Parker, T. J., and Pallanck, L. J. (2005). Genetic and genomic studies of Drosophila parkin mutants implicate oxidative stress and innate immune responses in pathogenesis. Hum. Mol. Genet. 14, 799-811. doi: 10.1093/hmg/ddi074

Greene, J. C., Whitworth, A. J., Kuo, I., Andrews, L. A., Feany, M. B., and Pallanck, L. J. (2003). Mitochondrial pathology and apoptotic muscle degeneration in Drosophila parkin mutants. Proc. Natl. Acad. Sci. U.S.A. 100, 4078-4083. doi: $10.1073 /$ pnas.0737556100

Groth, C., Sasamura, T., Khanna, M. R., Whitley, M., and Fortini, M. E. (2013). Protein trafficking abnormalities in Drosophila tissues with impaired activity of the ZIP7 zinc transporter Catsup. Development 140, 3018-3027. doi: $10.1242 /$ dev.088336

Grubman, A., and White, A. R. (2014). Copper as a key regulator of cell signalling pathways. Expert Rev. Mol. Med. 16:e11. doi: 10.1017/erm.2014.11

Grzywacz, A., Gdula-Argasinska, J., Muszynska, B., Tyszka-Czochara, M., Librowski, T., and Opoka, W. (2015). Metal responsive transcription factor 1 (MTF-1) regulates zinc dependent cellular processes at the molecular level. Acta Biochim. Pol. 62, 491-498. doi: 10.18388/abp.2015_1038

Guan, D., Mo, F., Han, Y., Gu, W., and Zhang, M. (2015). Digital gene expression profiling (DGE) of cadmium-treated Drosophila melanogaster. Environ. Toxicol. Pharmacol. 39, 300-306. doi: 10.1016/j.etap.2014.11.024

Guirola, M., Naranjo, Y., Capdevila, M., and Atrian, S. (2011). Comparative genomics analysis of metallothioneins in twelve Drosophila species. J. Inorg. Biochem. 105, 1050-1059. doi: 10.1016/j.jinorgbio.2011.05.004

Günes, C., Heuchel, R., Georgiev, O., Müller, K. H., Lichtlen, P., Blüthmann, H., et al. (1998). Embryonic lethality and liver degeneration in mice lacking the metal-responsive transcriptional activator MTF-1. EMBO J. 17, 2846-2854. doi: $10.1093 / \mathrm{emboj} / 17.10 .2846$

Günther, V., Lindert, U., and Schaffner, W. (2012a). The taste of heavy metals: gene regulation by MTF-1. Biochim. Biophys. Acta 1823, 1416-1425. doi: 10.1016/j.bbamcr.2012.01.005

Gunther, V., Waldvogel, D., Nosswitz, M., Georgiev, O., and Schaffner, W. (2012b). Dissection of Drosophila MTF-1 reveals a domain for differential target gene activation upon copper overload vs. copper starvation. Int. J. Biochem. Cell Biol. 44, 404-411. doi: 10.1016/j.biocel.2011.11.016
Gutiérrez, L., Sabaratnam, N., Aktar, R., Bettedi, L., Mandilaras, K., and Missirlis, F. (2010). Zinc accumulation in heterozygous mutants of fumble, the pantothenate kinase homologue of Drosophila. FEBS Lett. 584, 2942-2946. doi: 10.1016/j.febslet.2010.05.029

Hagmeyer, S., Haderspeck, J. C., and Grabrucker, A. M. (2014). Behavioral impairments in animal models for zinc deficiency. Front. Behav. Neurosci. 8:443. doi: $10.3389 /$ fnbeh.2014.00443

Harris, E. D. (2001). Copper homeostasis: the role of cellular transporters. Nutr. Rev. 59, 281-285. doi: 10.1111/j.1753-4887.2001.tb07017.x

He, T., Hirsch, H. V. B., Ruden, D. M., and Lnenicka, G. A. (2009). Chronic lead exposure alters presynaptic calcium regulation and synaptic facilitation in Drosophila larvae. Neurotoxicology 30, 777-784. doi: 10.1016/j.neuro.2009.08.007

Helfand, S. L., and Rogina, B. (2003). Genetics of aging in the fruit fly, Drosophila melanogaster. Annu. Rev. Genet. 37, 329-348. doi: 10.1146/annurev.genet.37.040103.095211

Hua, H., Georgiev, O., Schaffner, W., and Steiger, D. (2010). Human copper transporter Ctr1 is functional in Drosophila, revealing a high degree of conservation between mammals and insects. J. Biol. Inorg. Chem. 15, 107-113. doi: 10.1007/s00775-009-0599-0

Hua, H., Günther, V., Georgiev, O., and Schaffner, W. (2011a). Distorted copper homeostasis with decreased sensitivity to cisplatin upon chaperone Atox1 deletion in Drosophila. Biometals 24, 445-453. doi: 10.1007/s10534-0119438-1

Hua, H., Münter, L., Harmeier, A., Georgiev, O., Multhaup, G., and Schaffner, W. (2011b). Toxicity of Alzheimer's disease-associated Abeta peptide is ameliorated in a Drosophila model by tight control of zinc and copper availability. Biol. Chem. 392, 919-926. doi: 10.1515/BC.2011.084

Huang, M. L., Becker, E. M., Whitnall, M., Suryo Rahmanto, Y., Ponka, P., and Richardson, D. R. (2009). Elucidation of the mechanism of mitochondrial iron loading in Friedreich's ataxia by analysis of a mouse mutant. Proc. Natl. Acad. Sci. U.S.A. 106, 16381-16386. doi: 10.1073/pnas.0906784106

Huang, Y., Wu, Z., Cao, Y., Lang, M., Lu, B., and Zhou, B. (2014). Zinc binding directly regulates tau toxicity independent of tau hyperphosphorylation. Cell Rep. 8, 831-842. doi: 10.1016/j.celrep.2014.06.047

Hwang, J. E., de Bruyne, M., Warr, C. G., and Burke, R. (2014). Copper overload and deficiency both adversely affect the central nervous system of Drosophila. Metallomics 6, 2223-2229. doi: 10.1039/C4MT00140K

Jürgens, G., Wieschaus, E., Nüsslein-Volhard, C., and Kluding, H. (1984). Mutations affecting the pattern of the larval cuticle in Drosophila melanogaster: II. Zygotic loci on the third chromosome. Wilhelm Roux Arch. Dev. Biol. 193, 283-295. doi: 10.1007/BF00848157

Kakhlon, O., Manning, H., Breuer, W., Melamed-Book, N., Lu, C., Cortopassi, G., et al. (2008). Cell functions impaired by frataxin deficiency are restored by drug-mediated iron relocation. Blood 112, 5219-5227. doi: 10.1182/blood-2008-06-161919

Kaler, S. G. (2011). ATP7A-related copper transport diseases-emerging concepts and future trends. Nat. Rev. Neurol. 7, 15-29. doi: 10.1038/nrneurol.2010.180

Kambe, T., Hashimoto, A., and Fujimoto, S. (2014). Current understanding of ZIP and ZnT zinc transporters in human health and diseases. Cell. Mol. Life. Sci. 71, 3281-3295. doi: 10.1007/s00018-014-1617-0

Kambe, T., Tsuji, T., Hashimoto, A., and Itsumura, N. (2015). The physiological, biochemical, and molecular roles of zinc transporters in zinc homeostasis and metabolism. Physiol. Rev. 95, 749-784. doi: 10.1152/physrev.00035.2014

Kelly, E. J., Quaife, C. J., Froelick, G. J., and Palmiter, R. D. (1996). Metallothionein I and II protect against zinc deficiency and zinc toxicity in mice. J. Nutr. 126, 1782-1790.

Kim, B.-E., Turski, M. L., Nose, Y., Casad, M., Rockman, H. A., and Thiele, D. J. (2010). Cardiac copper deficiency activates a systemic signaling mechanism that communicates with the copper acquisition and storage organs. Cell Metab. 11, 353-363. doi: 10.1016/j.cmet.2010.04.003

Kirby, K., Jensen, L. T., Binnington, J., Hilliker, A. J., Ulloa, J., Culotta, V. C., et al. (2008). Instability of superoxide dismutase 1 of Drosophila in mutants deficient for its cognate copper chaperone. J. Biol. Chem. 283, 35393-35401. doi: 10.1074/jbc.M807131200

Koeppen, A. H., Kuntzsch, E. C., Bjork, S. T., Ramirez, R. L., Mazurkiewicz, J. E., and Feustel, P. J. (2013). Friedreich ataxia: metal dysmetabolism in dorsal root ganglia. Acta Neuropathol. Commun. 1:26. doi: 10.1186/2051-5960-1-26 
Koeppen, A. H., Ramirez, R. L., Yu, D., Collins, S. E., Qian, J., Parsons, P. J., et al. (2012). Friedreich's ataxia causes redistribution of iron, copper, and zinc in the dentate nucleus. Cerebellum 11, 845-860. doi: 10.1007/s12311-012-0383-5

Konopka, R. J., and Benzer, S. (1971). Clock mutants of Drosophila melanogaster. Proc. Natl. Acad. Sci. U.S.A. 68, 2112-2116. doi: 10.1073/pnas.68.9.2112

Krezel, A., and Maret, W. (2017). The functions of metamorphic metallothioneins in zinc and copper metabolism. Int. J. Mol. Sci. 18:1237. doi: $10.3390 /$ ijms 18061237

Lang, M., Fan, Q., Wang, L., Zheng, Y., Xiao, G., Wang, X., et al. (2013). Inhibition of human high-affinity copper importer Ctr1 orthologous in the nervous system of Drosophila ameliorates Abeta42-induced Alzheimer's disease-like symptoms. Neurobiol. Aging 34, 2604-2612. doi: 10.1016/j.neurobiolaging.2013.05.029

Lang, M., Wang, L., Fan, Q., Xiao, G., Wang, X., Zhong, Y., et al. (2012). Genetic inhibition of solute-linked carrier 39 family transporter 1 ameliorates abeta pathology in a Drosophila model of Alzheimer's disease. PLoS Genet. 8:e1002683. doi: 10.1371/journal.pgen.1002683

Laukens, D., Waeytens, A., De Bleser, P., Cuvelier, C., and De Vos, M. (2009). Human metallothionein expression under normal and pathological conditions: mechanisms of gene regulation based on in silico promoter analysis. Crit. Rev. Eukaryot. Gene Expr. 19, 301-317. doi: 10.1615/CritRevEukarGeneExpr.v19.i4.40

Le Manh, H., Guio, L., Merenciano, M., Rovira, Q., Barrón, M. G., and González, J. (2017). Natural and laboratory mutations in kuzbanian are associated with zinc stress phenotypes in Drosophila melanogaster. Sci. Rep. 7:42663. doi: $10.1038 /$ srep 42663

Lenartowicz, M., Krzeptowski, W., Lipinski, P., Grzmil, P., Starzynski, R., Pierzchała, O., et al. (2015). Mottled mice and non-mammalian models of menkes disease. Front. Mol. Neurosci. 8:72. doi: 10.3389/fnmol.2015.00072

Letelier, M. E., Faúndez, M., Jara-Sandoval, J., Molina-Berríos, A., CortésTroncoso, J., Aracena-Parks, P., et al. (2009). Mechanisms underlying the inhibition of the cytochrome P450 system by copper ions. J. Appl. Toxicol. 29, 695-702. doi: $10.1002 /$ jat. 1460

Lichten, L. A., and Cousins, R. J. (2009). Mammalian zinc transporters: nutritional and physiologic regulation. Annu. Rev. Nutr. 29, 153-176. doi: 10.1146/annurev-nutr-033009-083312

Liu, B., Moloney, A., Meehan, S., Morris, K., Thomas, S. E., Serpell, L. C., et al. (2011). Iron promotes the toxicity of amyloid beta peptide by impeding its ordered aggregation. J. Biol. Chem. 286, 4248-4256. doi: 10.1074/jbc.M110.158980

Liuzzi, J. P., Guo, L., Yoo, C., and Stewart, T. S. (2014). Zinc and autophagy. Biometals 27, 1087-1096. doi: 10.1007/s10534-014-9773-0

Lutsenko, S., Barnes, N. L., Bartee, M. Y., and Dmitriev, O. Y. (2007). Function and regulation of human copper-transporting ATPases. Physiol. Rev. 87, 1011-1046. doi: 10.1152/physrev.00004.2006

Lye, J. C., Hwang, J. E. C., Paterson, D., de Jonge, M. D., Howard, D. L., and Burke, R. (2011). Detection of genetically altered copper levels in Drosophila tissues by synchrotron x-ray fluorescence microscopy. PLoS ONE 6:e26867. doi: 10.1371/journal.pone.0026867

Lye, J. C., Richards, C. D., Dechen, K., Paterson, D., de Jonge, M. D., Howard, D. L., et al. (2012). Systematic functional characterization of putative zinc transport genes and identification of zinc toxicosis phenotypes in Drosophila melanogaster. J. Exp. Biol. 215, 3254-3265. doi: 10.1242/jeb.069260

Lye, J. C., Richards, C. D., Dechen, K., Warr, C. G., and Burke, R. (2013). In vivo zinc toxicity phenotypes provide a sensitized background that suggests zinc transport activities for most of the Drosophila Zip and $\mathrm{ZnT}$ genes. J. Biol. Inorg. Chem. 18, 323-332. doi: 10.1007/s00775-013-0976-6

Madsen, E., and Gitlin, J. D. (2007). Copper and iron disorders of the brain. Annu. Rev. Neurosci. 30, 317-337. doi: 10.1146/annurev.neuro.30.051606.094232

Mandilaras, K., Pathmanathan, T., and Missirlis, F. (2013). Iron absorption in Drosophila melanogaster. Nutrients 5, 1622-1647. doi: 10.3390/nu5051622

Maroni, G., Lastowski-Perry, D., Otto, E., and Watson, D. (1986). Effects of heavy metals on Drosophila larvae and a metallothionein cDNA. Environ. Health Perspect. 65, 107-116.

Marshall, O. J., Southall, T. D., Cheetham, S. W., and Brand, A. H. (2016). Celltype-specific profiling of protein-DNA interactions without cell isolation using targeted DamID with next-generation sequencing. Nat. Protoc. 11, 1586-1598. doi: $10.1038 /$ nprot.2016.084
Masters, B. A., Kelly, E. J., Quaife, C. J., Brinster, R. L., and Palmiter, R. D. (1994), Targeted disruption of metallothionein I and II genes increases sensitivity to cadmium. Proc. Natl. Acad. Sci. U.S.A. 91, 584-588. doi: 10.1073/pnas.91.2.584

Mathews, W. R., Ong, D., Milutinovich, A. B., and Van Doren, M. (2006). Zinc transport activity of Fear of Intimacy is essential for proper gonad morphogenesis and DE-cadherin expression. Development 133, 1143-1153. doi: $10.1242 /$ dev.02256

Mathews, W. R., Wang, F., Eide, D. J., and van Doren, M. (2005). Drosophila fear of intimacy encodes a Zrt/IRT-like protein (ZIP) family zinc transporter functionally related to mammalian ZIP proteins. J. Biol. Chem. 280, 787-795. doi: 10.1074/jbc.M411308200

McAllum, E. J., and Finkelstein, D. I. (2016). Metals in Alzheimer's and Parkinson's disease: relevance to dementia with lewy bodies. J. Mol. Neurosci. 60, 279-288. doi: 10.1007/s12031-016-0809-5

Mercer, S. W., La Fontaine, S., Warr, C. G., and Burke, R. (2016). Reduced glutathione biosynthesis in Drosophila melanogaster causes neuronal defects linked to copper deficiency. J. Neurochem. 137, 360-370. doi: 10.1111/jnc. 13567

Mercer, S. W., Wang, J., and Burke, R. (2017). In vivo modeling of the pathogenic effect of copper transporter mutations that cause menkes and wilson diseases, motor neuropathy, and susceptibility to Alzheimer's disease. J. Biol. Chem. 292, 4113-4122. doi: 10.1074/jbc.M116.756163

Meyer, S., Schulz, J., Jeibmann, A., Taleshi, M. S., Ebert, F., Francesconi, K. A., et al. (2014). Arsenic-containing hydrocarbons are toxic in the in vivo model Drosophila melanogaster. Metallomics 6, 2010-2014. doi: $10.1039 / \mathrm{C} 4 \mathrm{MT} 00249 \mathrm{~K}$

M Fetherolf, M., Boyd, S. D., Winkler, D. D., and Winge, D. R. (2017). Oxygen-dependent activation of $\mathrm{Cu}, \mathrm{Zn}$-superoxide dismutase-1. Metallomics 9, 1047-1059. doi: 10.1039/C6MT00298F

Mohr, S. E., Rudd, K., Hu, Y., Song, W. R., Gilly, Q., Buckner, M., et al. (2017). Zinc detoxification: a functional genomics and transcriptomics analysis in Drosophila melanogaster cultured cells. G3 (Bethesda, MD.). doi: 10.1534/g3. 117.300447. [Epub ahead of print].

Molnar, J., Ujfaludi, Z., Fong, S. F. T., Bollinger, J. A., Waro, G., Fogelgren, B., et al. (2005). Drosophila lysyl oxidases Dmloxl-1 and Dmloxl-2 are differentially expressed and the active DmLOXL-1 influences gene expression and development. J. Biol. Chem. 280, 22977-22985. doi: 10.1074/jbc.M503006200

Monastirioti, M., Linn, C. E., and White, K. (1996). Characterization of Drosophila tyramine beta-hydroxylase gene and isolation of mutant flies lacking octopamine. J. Neurosci. 16, 3900-3911.

Morgan, T. H. (1910). Sex limited inheritance in Drosophila. Science 32, 120-122. doi: $10.1126 /$ science. 32.812 .120

Mummery-Widmer, J. L., Yamazaki, M., Stoeger, T., Novatchkova, M., Bhalerao, S., Chen, D., et al. (2009). Genome-wide analysis of Notch signalling in Drosophila by transgenic RNAi. Nature 458, 987-992. doi: 10.1038/nature07936

Myers, E. W., Sutton, G. G., Delcher, A. L., Dew, I. M., Fasulo, D. P., Flanigan, M. J., et al. (2000). A whole-genome assembly of Drosophila. Science 287, 2196-2204. doi: 10.1126/science.287.5461.2196

Nagarkar-Jaiswal, S., DeLuca, S. Z., Lee, P.-T., Lin, W.-W., Pan, H., Zuo, Z., et al. (2015a). A genetic toolkit for tagging intronic MiMIC containing genes. ELife 4:e08469. doi: 10.7554/eLife.08469

Nagarkar-Jaiswal, S., Lee, P.-T., Campbell, M. E., Chen, K., Anguiano-Zarate, S., Gutierrez, M. C., et al. (2015b). A library of MiMICs allows tagging of genes and reversible, spatial and temporal knockdown of proteins in Drosophila. ELife 4:e05338. doi: 10.7554/eLife.05338

Navarro, J. A., Botella, J. A., Metzendorf, C., Lind, M. I., and Schneuwly, S. (2015). Mitoferrin modulates iron toxicity in a Drosophila model of Friedreich's ataxia. Free Radic. Biol. Med. 85, 71-82. doi: 10.1016/j.freeradbiomed.2015. 03.014

Nevitt, T., Ohrvik, H., and Thiele, D. J. (2012). Charting the travels of copper in eukaryotes from yeast to mammals. Biochim. Biophys. Acta 1823, 1580-1593. doi: 10.1016/j.bbamcr.2012.02.011

Ni, J.-Q., Liu, L.-P., Binari, R., Hardy, R., Shim, H.-S., Cavallaro, A., et al. (2009). A Drosophila resource of transgenic RNAi lines for neurogenetics. Genetics 182, 1089-1100. doi: 10.1534/genetics.109.103630

Niehoff, A.-C., Bauer, O. B., Kröger, S., Fingerhut, S., Schulz, J., Meyer, S., et al. (2015). Quantitative bioimaging to investigate the uptake of mercury species in Drosophila melanogaster. Anal. Chem. 87, 10392-10396. doi: 10.1021/acs.analchem.5b02500 
Norgate, M., Lee, E., Southon, A., Farlow, A., Batterham, P., Camakaris, J., et al. (2006). Essential roles in development and pigmentation for the Drosophila copper transporter DmATP7. Mol. Biol. Cell 17, 475-484. doi: 10.1091/mbc.E05-06-0492

Norgate, M., Southon, A., Greenough, M., Cater, M., Farlow, A., Batterham, P., et al. (2010). Syntaxin 5 is required for copper homeostasis in Drosophila and mammals. PLoS ONE 5:e14303. doi: 10.1371/journal.pone.0014303

Norgate, M., Southon, A., Zou, S., Zhan, M., Sun, Y., Batterham, P., et al. (2007). Copper homeostasis gene discovery in Drosophila melanogaster. Biometals 20, 683-697. doi: 10.1007/s10534-006-9075-2

Opazo, C. M., Greenough, M. A., and Bush, A. I. (2014). Copper: from neurotransmission to neuroproteostasis. Front. Aging Neurosci. 6:143. doi: 10.3389/fnagi.2014.00143

Ortiz, J. G. M., Opoka, R., Kane, D., and Cartwright, I. L. (2009). Investigating arsenic susceptibility from a genetic perspective in Drosophila reveals a key role for glutathione synthetase. Toxicol. Sci. 107, 416-426. doi: $10.1093 /$ toxsci/kfn192

Osredkar, J. (2011). Copper and Zinc, biological role and significance of copper/zinc imbalance. J. Clin. Toxicol. S3:001. doi: 10.4172/2161-0495. S3-001

Ott, S., Dziadulewicz, N., and Crowther, D. C. (2015). Iron is a specific cofactor for distinct oxidation- and aggregation-dependent Abeta toxicity mechanisms in a Drosophila model. Dis. Model. Mech. 8, 657-667. doi: 10.1242/dmm.019042

Palmiter, R. D. (1998). The elusive function of metallothioneins. Proc. Natl. Acad. Sci. U.S.A. 95, 8428-8430. doi: 10.1073/pnas.95.15.8428

Palumaa, P. (2013). Copper chaperones. The concept of conformational control in the metabolism of copper. FEBS Lett. 587, 1902-1910. doi: 10.1016/j.febslet.2013.05.019

Pérez-Rafael, S., Kurz, A., Guirola, M., Capdevila, M., Palacios, O., and Atrian, S. (2012). Is MtnE, the fifth Drosophila metallothionein, functionally distinct from the other members of this polymorphic protein family? Metallomics 4, 342-349. doi: $10.1039 / \mathrm{c} 2 \mathrm{mt} 00182 \mathrm{a}$

Phillips, J. P., Campbell, S. D., Michaud, D., Charbonneau, M., and Hilliker, A. J. (1989). Null mutation of copper/zinc superoxide dismutase in Drosophila confers hypersensitivity to paraquat and reduced longevity. Proc. Natl. Acad. Sci. U.S.A. 86, 2761-2765. doi: 10.1073/pnas.86.8.2761

Pielage, J., Kippert, A., Zhu, M., and Klämbt, C. (2004). The Drosophila transmembrane protein Fear-of-intimacy controls glial cell migration. Dev. Biol. 275, 245-257. doi: 10.1016/j.ydbio.2004.07.039

Porcelli, D., Oliva, M., Duchi, S., Latorre, D., Cavaliere, V., Barsanti, P., et al. (2010). Genetic, functional and evolutionary characterization of scox, the Drosophila melanogaster ortholog of the human SCO1 gene. Mitochondrion 10, 433-448. doi: 10.1016/j.mito.2010.04.002

Port, F., and Bullock, S. L. (2016). Augmenting CRISPR applications in Drosophila with tRNA-flanked sgRNAs. Nat. Methods 13, 852-854. doi: 10.1038/nmeth.3972

Poujois, A., Devedjian, J.-C., Moreau, C., Devos, D., Chaine, P., Woimant, F., et al. (2016). Bioavailable trace metals in neurological diseases. Curr. Treat. Options Neurol. 18:46. doi: 10.1007/s11940-016-0426-1

Poulson, D. F., Bowen, V. T., Hilse, R. M., and Rubinson, A. C. (1952). The copper metabolism of Drosophila. Proc. Natl. Acad. Sci. U.S.A. 38, 912-921. doi: $10.1073 /$ pnas.38.10.912

Qin, Q., Wang, X., and Zhou, B. (2013). Functional studies of Drosophila zinc transporters reveal the mechanism for dietary zinc absorption and regulation. BMC Biol. 11:101. doi: 10.1186/1741-7007-11-101

Raudenska, M., Gumulec, J., Podlaha, O., Sztalmachova, M., Babula, P., Eckschlager, T., et al. (2014). Metallothionein polymorphisms in pathological processes. Metallomics 6, 55-68. doi: 10.1039/C3MT00132F

Reddy, P., Zehring, W. A., Wheeler, D. A., Pirrotta, V., Hadfield, C., Hall, J. C., et al. (1984). Molecular analysis of the period locus in Drosophila melanogaster and identification of a transcript involved in biological rhythms. Cell 38, 701-710. doi: 10.1016/0092-8674(84)90265-4

Reiter, L. T., Potocki, L., Chien, S., Gribskov, M., and Bier, E. (2001). A systematic analysis of human disease-associated gene sequences in Drosophila melanogaster. Genome Res. 11, 1114-1125. doi: 10.1101/gr.169101

Renton, A. E., Chiò, A., and Traynor, B. J. (2014). State of play in amyotrophic lateral sclerosis genetics. Nat. Neurosci. 17, 17-23. doi: 10.1038/nn.3584
Riabinina, O., Luginbuhl, D., Marr, E., Liu, S., Wu, M. N., Luo, L., et al. (2015) Improved and expanded Q-system reagents for genetic manipulations. Nat. Methods 12, 219-222. doi: 10.1038/nmeth.3250

Richards, C. D., and Burke, R. (2015). Local and systemic effects of targeted zinc redistribution in Drosophila neuronal and gastrointestinal tissues. Biometals 28, 967-974. doi: 10.1007/s10534-015-9881-5

Richards, C. D., Warr, C. G., and Burke, R. (2015). A role for dZIP89B in Drosophila dietary zinc uptake reveals additional complexity in the zinc absorption process. Int. J. Biochem. Cell Biol. 69, 11-19. doi: 10.1016/j.biocel.2015.10.004

Richards, C. D., Warr, C. G., and Burke, R. (2017). A role for the Drosophila zinc transporter Zip88E in protecting against dietary zinc toxicity. PLoS ONE 12:e0181237. doi: 10.1371/journal.pone.0181237

Rival, T., Page, R. M., Chandraratna, D. S., Sendall, T. J., Ryder, E., Liu, B., et al. (2009). Fenton chemistry and oxidative stress mediate the toxicity of the betaamyloid peptide in a Drosophila model of Alzheimer's disease. Eur. J. Neurosci. 29, 1335-1347. doi: 10.1111/j.1460-9568.2009.06701.x

Rotilio, G., Carrì, M. T., Rossi, L., and Ciriolo, M. R. (2000). Copperdependent oxidative stress and neurodegeneration. IUBMB Life 50, 309-314. doi: 10.1080/15216540051081074

Rovenko, B. M., Perkhulyn, N. V., Lushchak, O. V., Storey, J. M., Storey, K. B., and Lushchak, V. I. (2014). Molybdate partly mimics insulin-promoted metabolic effects in Drosophila melanogaster. Comp. Biochem. Physiol. Toxicol. Pharmacol. 165, 76-82. doi: 10.1016/j.cbpc.2014.06.002

Rubin, G. M., and Spradling, A. C. (1982). Genetic transformation of Drosophila with transposable element vectors. Science 218, 348-353. doi: $10.1126 /$ science.6289436

Saini, N., Oelhafen, S., Hua, H., Georgiev, O., Schaffner, W., and Büeler, H. (2010). Extended lifespan of Drosophila parkin mutants through sequestration of redox-active metals and enhancement of anti-oxidative pathways. Neurobiol. Dis. 40, 82-92. doi: 10.1016/j.nbd.2010.05.011

Saini, N., and Schaffner, W. (2010). Zinc supplement greatly improves the condition of parkin mutant Drosophila. Biol. Chem. 391, 513-518. doi: 10.1515/bc. 2010.052

Sanokawa-Akakura, R., Cao, W., Allan, K., Patel, K., Ganesh, A., Heiman, G., et al. (2010). Control of Alzheimer's amyloid beta toxicity by the high molecular weight immunophilin FKBP52 and copper homeostasis in Drosophila. PLoS ONE 5:e8626. doi: 10.1371/journal.pone.0008626

Sarov, M., Barz, C., Jambor, H., Hein, M. Y., Schmied, C., Suchold, D., et al. (2016). A genome-wide resource for the analysis of protein localisation in Drosophila. Elife 5:e12068. doi: 10.7554/eLife.12068

Schmucker, S., Martelli, A., Colin, F., Page, A., Wattenhofer-Donzé, M., Reutenauer, L., et al. (2011). Mammalian frataxin: an essential function for cellular viability through an interaction with a preformed ISCU/NFS1/ISD11 iron-sulfur assembly complex. PLoS ONE 6:e16199. doi: 10.1371/journal.pone.0016199

Schofield, R. M., Postlethwait, J. H., and Lefevre, H. W. (1997). MeV-ion microprobe analyses of whole Drosophila suggest that zinc and copper accumulation is regulated storage not deposit excretion. J. Exp. Biol. 200, 3235-3243.

Sellami, A., Wegener, C., and Veenstra, J. A. (2012). Functional significance of the copper transporter ATP7 in peptidergic neurons and endocrine cells in Drosophila melanogaster. FEBS Lett. 586, 3633-3638. doi: 10.1016/j.febslet.2012.08.009

Selvaraj, A., Balamurugan, K., Yepiskoposyan, H., Zhou, H., Egli, D., Georgiev, O., et al. (2005). Metal-responsive transcription factor (MTF-1) handles both extremes, copper load and copper starvation, by activating different genes. Genes Dev. 19, 891-896. doi: 10.1101/gad.1301805

Sensi, S. L., Paoletti, P., Bush, A. I., and Sekler, I. (2009). Zinc in the physiology and pathology of the CNS. Nat. Rev. Neurosci. 10, 780-791. doi: 10.1038/nrn2734

Sensi, S. L., Paoletti, P., Koh, J.-Y., Aizenman, E., Bush, A. I., and Hershfinkel, M. (2011). The neurophysiology and pathology of brain zinc. J. Neurosci. 31, 16076-16085. doi: 10.1523/JNEUROSCI.3454-11.2011

Singh, S. K., Sinha, P., Mishra, L., and Srikrishna, S. (2013). Neuroprotective role of a novel copper chelator against $\mathrm{A} \beta 42$ induced neurotoxicity. Int. J. Alzheimers Dis. 2013:567128. doi: 10.1155/2013/567128

Soriano, S., Calap-Quintana, P., Llorens, J. V., Al-Ramahi, I., Gutiérrez, L., Martínez-Sebastián, M. J., et al. (2016). Metal homeostasis regulators 
suppress FRDA phenotypes in a Drosophila model of the disease. PLoS ONE 11:e0159209. doi: 10.1371/journal.pone.0159209

Soriano, S., Llorens, J. V., Blanco-Sobero, L., Gutiérrez, L., Calap-Quintana, P., Morales, M. P., et al. (2013). Deferiprone and idebenone rescue frataxin depletion phenotypes in a Drosophila model of Friedreich's ataxia. Gene 521, 274-281. doi: 10.1016/j.gene.2013.02.049

Southall, T. D., Gold, K. S., Egger, B., Davidson, C. M., Caygill, E. E., Marshall, O. J., et al. (2013). Cell-type-specific profiling of gene expression and chromatin binding without cell isolation: assaying RNA Pol II occupancy in neural stem cells. Dev. Cell 26, 101-112. doi: 10.1016/j.devcel.2013.05.020

Southon, A., Burke, R., and Camakaris, J. (2013a). What can flies tell us about copper homeostasis? Metallomics 5, 1346-1356. doi: 10.1039/c3mt00105a.

Southon, A., Burke, R., Norgate, M., Batterham, P., and Camakaris, J. (2004). Copper homoeostasis in Drosophila melanogaster S2 cells. Biochem. J. 383, 303-309. doi: 10.1042/BJ20040745

Southon, A., Farlow, A., Norgate, M., Burke, R., and Camakaris, J. (2008). Malvolio is a copper transporter in Drosophila melanogaster. J. Exp. Biol. 211, 709-716. doi: $10.1242 /$ jeb. 014159

Southon, A., Greenough, M. A., Ganio, G., Bush, A. I., Burke, R., and Camakaris, J. (2013b). Presenilin promotes dietary copper uptake. PLOS ONE 8:e62811. doi: 10.1371/journal.pone.0062811

Southon, A., Greenough, M., Hung, Y. H., Norgate, M., Burke, R., and Camakaris, J. (2011). The ADP-ribosylation factor 1 (Arf1) is involved in regulating copper uptake. Int. J. Biochem. Cell Biol. 43, 146-153. doi: 10.1016/j.biocel.2010.10.012

Southon, A., Palstra, N., Veldhuis, N., Gaeth, A., Robin, C., Burke, R., et al. (2010). Conservation of copper-transporting $\mathrm{P}(\mathrm{IB})$-type ATPase function. Biometals 23, 681-694. doi: 10.1007/s10534-010-9332-2

Stathakis, D. G., Burton, D. Y., McIvor, W. E., Krishnakumar, S., Wright, T. R., and O'Donnell, J. M. (1999). The catecholamines up (Catsup) protein of Drosophila melanogaster functions as a negative regulator of tyrosine hydroxylase activity. Genetics 153, 361-382.

Steiger, D., Fetchko, M., Vardanyan, A., Atanesyan, L., Steiner, K., Turski, M. L., et al. (2010). The Drosophila copper transporter Ctr1C functions in male fertility. J. Biol. Chem. 285, 17089-17097. doi: 10.1074/jbc.M109.090282

Stiller, I., Lizák, B., and Bánhegyi, G. (2014). Physiological functions of presenilins; beyond $\gamma$-secretase. Curr. Pharm. Biotechnol. 15, 1019-1025. doi: $10.2174 / 1389201015666141122204139$

Stuart, G. W., Searle, P. F., and Palmiter, R. D. (1985). Identification of multiple metal regulatory elements in mouse metallothionein-I promoter by assaying synthetic sequences. Nature 317, 828-831. doi: 10.1038/317828a0

Tejeda-Guzmán, C., Rosas-Arellano, A., Kroll, T., Webb, S. M., Barajas-Aceves, M., Osorio, B., et al. (2017). Zinc storage granules in the Malpighian tubules of Drosophila melanogaster. BioRxiv. doi: 10.1101/159558

Ternes, A. P., Zemolin, A. P., da Cruz, L. C., da Silva, G. F., Saidelles, A. P. F., and de Paula, M. T., et al. (2014). Drosophila melanogaster-an embryonic model for studying behavioral and biochemical effects of manganese exposure. EXCLI J. $13,1239-1253$

Terrin, G., Berni Canani, R., Di Chiara, M., Pietravalle, A., Aleandri, V., Conte, F., et al. (2015). Zinc in early life: a key element in the fetus and preterm neonate. Nutrients 7, 10427-10446. doi: 10.3390/nu7125542

Tsunemi, T., and Krainc, D. (2014). $\mathrm{Zn}^{2}$ ? dyshomeostasis caused by loss of ATP13A2/PARK9 leads to lysosomal dysfunction and alpha-synuclein accumulation. Hum. Mol. Genet. 23, 2791-2801. doi: 10.1093/hmg/ddt572

Turski, M. L., Brady, D. C., Kim, H. J., Kim, B.-E., Nose, Y., Counter, C. M., et al. (2012). A novel role for copper in Ras/mitogen-activated protein kinase signaling. Mol. Cell. Biol. 32, 1284-1295. doi: 10.1128/MCB.05722-11

Turski, M. L., and Thiele, D. J. (2007). Drosophila Ctr1A functions as a copper transporter essential for development. J. Biol. Chem. 282, 24017-24026. doi: 10.1074/jbc.M703792200

Vallee, B. L., and Falchuk, K. H. (1993). The biochemical basis of zinc physiology. Physiol. Rev. 73, 79-118.

van Doren, M. (2003). fear of intimacy encodes a novel transmembrane protein required for gonad morphogenesis in Drosophila. Development 130, 2355-2364. doi: 10.1242/dev.00454

Venken, K. J., Schulze, K. L., Haelterman, N. A., Pan, H., He, Y., Evans-Holm, M., et al. (2011). MiMIC: a highly versatile transposon insertion resource for engineering Drosophila melanogaster genes. Nat. Methods 8, 737-743. doi: $10.1038 /$ nmeth.1662
Wang, J., Binks, T., Warr, C. G., and Burke, R. (2014). Vacuolar-type $\mathrm{H}^{+}$-ATPase subunits and the neurogenic protein big brain are required for optimal copper and zinc uptake. Metallomics 6, 2100-2108. doi: 10.1039/C4MT00196F

Wang, X., Wu, Y., and Zhou, B. (2009). Dietary zinc absorption is mediated by ZnT1 in Drosophila melanogaster. FASEB J. 23, 2650-2661. doi: 10.1096/fj.08-126649

Wang, Y., Wimmer, U., Lichtlen, P., Inderbitzin, D., Stieger, B., Meier, P. J., et al. (2004). Metal-responsive transcription factor-1 (MTF-1) is essential for embryonic liver development and heavy metal detoxification in the adult liver. FASEB J. 18, 1071-1079. doi: 10.1096/fj.03-1282com

Wang, Z., Ferdousy, F., Lawal, H., Huang, Z., Daigle, J. G., Izevbaye, I., et al. (2011). Catecholamines up integrates dopamine synthesis and synaptic trafficking. $J$. Neurochem. 119, 1294-1305. doi: 10.1111/j.1471-4159.2011.07517.x

White, A. R., Multhaup, G., Maher, F., Bellingham, S., Camakaris, J., Zheng, H., et al. (1999). The Alzheimer's disease amyloid precursor protein modulates copper-induced toxicity and oxidative stress in primary neuronal cultures. J. Neurosci. 19, 9170-9179.

Whitnall, M., Suryo Rahmanto, Y., Sutak, R., Xu, X., Becker, E. M., Mikhael, M. R., et al. (2008). The MCK mouse heart model of Friedreich's ataxia: alterations in iron-regulated proteins and cardiac hypertrophy are limited by iron chelation. Proc. Natl. Acad. Sci. U.S.A. 105, 9757-9762. doi: 10.1073/pnas.0804261105

Wieschaus, E., Nüsslein-Volhard, C., and Jürgens, G. (1984). Mutations affecting the pattern of the larval cuticle in Drosophila melanogaster: III. Zygotic loci on the X-chromosome and fourth chromosome. Wilhelm Roux Arch. Dev. Biol. 193, 296-307. doi: 10.1007/BF00848158

Wright, T. R. F. (1987). "The Genetics Of Biogenic Amine Metabolism, Sclerotization, And Melanization In Drosophila Melanogaster** This review is dedicated to Professor Ernst Caspari in recognition of his pioneering research in biochemical genetics," in Molecular Genetics of Development, ed J. G. Scandalios (San Diego, CA: Academic Press), 127-222.

Wu, Z., Du, Y., Xue, H., Wu, Y., and Zhou, B. (2012). Aluminum induces neurodegeneration and its toxicity arises from increased iron accumulation and reactive oxygen species (ROS) production. Neurobiol. Aging 33, 199, e1-12. doi: 10.1016/j.neurobiolaging.2010.06.018

Xiao, G., Fan, Q., Wang, X., and Zhou, B. (2013). Huntington disease arises from a combinatory toxicity of polyglutamine and copper binding. Proc. Natl. Acad. Sci. U.S.A. 110, 14995-15000. doi: 10.1073/pnas.1308535110

Xiao, G., Wan, Z., Fan, Q., Tang, X., and Zhou, B. (2014). The metal transporter ZIP13 supplies iron into the secretory pathway in Drosophila melanogaster. Elife 3:e03191. doi: 10.7554/eLife.03191

Xie, J., Owen, T., Xia, K., Singh, A. V., Tou, E., Li, L., et al. (2015). Zinc inhibits Hedgehog autoprocessing: linking zinc deficiency with Hedgehog activation. J. Biol. Chem. 290, 11591-11600. doi: 10.1074/jbc.M114.623264

$\mathrm{Xu}, \quad$ Z., Tito, A. J., Rui, Y.-N., and Zhang, S. (2015). Studying polyglutamine diseases in Drosophila. Exp. Neurol. 274, 25-41. doi: 10.1016/j.expneurol.2015.08.002

Yepiskoposyan, H., Egli, D., Fergestad, T., Selvaraj, A., Treiber, C., Multhaup, G., et al. (2006). Transcriptome response to heavy metal stress in Drosophila reveals a new zinc transporter that confers resistance to zinc. Nucleic Acids Res. 34, 4866-4877. doi: 10.1093/nar/gkl606

Yin, S., Qin, Q., and Zhou, B. (2017). Functional studies of Drosophila zinc transporters reveal the mechanism for zinc excretion in Malpighian tubules. BMC Biol. 15:12. doi: 10.1186/s12915-017-0355-9

Zalewski, P. D., Forbes, I. J., and Betts, W. H. (1993). Correlation of apoptosis with change in intracellular labile $\mathrm{Zn}$ (II) using zinquin (2-methyl-8-ptoluenesulphonamido-6-quinolyloxy)acetic acid, a new specific fluorescent probe for Zn(II). Biochem. J. 296(Pt 2), 403-408. doi: 10.1042/bj2960403

Zhang, B., Egli, D., Georgiev, O., and Schaffner, W. (2001). The Drosophila homolog of mammalian zinc finger factor MTF-1 activates transcription in response to heavy metals. Mol. Cell. Biol. 21, 4505-4514. doi: 10.1128/MCB.21.14.4505-4514.2001

Zhang, X., Koolhaas, W. H., and Schnorrer, F. (2014). A versatile two-step CRISPRand RMCE-based strategy for efficient genome engineering in Drosophila. G3 (Bethesda) 4, 2409-2418. doi: 10.1534/g3.114.013979

Zhou, H., Cadigan, K. M., and Thiele, D. J. (2003). A copper-regulated transporter required for copper acquisition, pigmentation, and specific stages of development in Drosophila melanogaster. J. Biol. Chem. 278, 48210-48218. doi: 10.1074/jbc.M309820200 
Zhou, S., Luoma, S. E., St Armour, G. E., Thakkar, E., Mackay, T. F. C., and Anholt, R. R. H. (2017). A Drosophila model for toxicogenomics: genetic variation in susceptibility to heavy metal exposure. PLoS Genet. 13:e1006907. doi: 10.1371/journal.pgen.1006907

Zhu, Z.-J., Wu, K.-C., Yung, W.-H., Qian, Z.-M., and Ke, Y. (2016). Differential interaction between iron and mutant alpha-synuclein causes distinctive Parkinsonian phenotypes in Drosophila. Biochim. Biophys. Acta 1862, 518-525. doi: 10.1016/j.bbadis.2016.01.002

Zlatic, S., Comstra, H. S., Gokhale, A., Petris, M. J., and Faundez, V. (2015). Molecular basis of neurodegeneration and neurodevelopmental defects in Menkes disease. Neurobiol. Dis. 81, 154-161. doi: 10.1016/j.nbd.2014.12.024
Conflict of Interest Statement: The authors declare that the research was conducted in the absence of any commercial or financial relationships that could be construed as a potential conflict of interest.

Copyright $\odot 2017$ Navarro and Schneuwly. This is an open-access article distributed under the terms of the Creative Commons Attribution License (CC BY). The use, distribution or reproduction in other forums is permitted, provided the original author(s) or licensor are credited and that the original publication in this journal is cited, in accordance with accepted academic practice. No use, distribution or reproduction is permitted which does not comply with these terms. 